\title{
Economic viability assessment of sustainable hydrogen production, storage, and utilisation technologies integrated into on- and off-grid micro-grids: A performance comparison of different meta-heuristics
}

\author{
Soheil Mohseni", Alan C. Brent \\ Chair in Sustainable Energy Systems, School of Engineering and Computer Science, Faculty of \\ Engineering, Victoria University of Wellington, PO Box 600, Wellington 6140, New Zealand \\ * Corresponding author, Email: soheil.mohseni@ecs.vuw.ac.nz
}

\begin{abstract}
In recent years, there has been considerable interest in the development of zero-emissions, sustainable energy systems utilising the potential of hydrogen energy technologies. However, the improper long-term economic assessment of costs and consequences of such hydrogen-based renewable energy systems has hindered the transition to the so-called hydrogen economy in many cases. One of the main reasons for this is the inefficiency of the optimization techniques employed to estimate the whole-life costs of such systems. Owing to the highly nonlinear and non-convex nature of the life-cycle cost optimization problems of sustainable energy systems using hydrogen as an energy carrier, metaheuristic optimization techniques must be utilised to solve them. To this end, using a specifically developed artificial intelligence-based micro-grid capacity planning method, this paper examines the performances of twenty metaheuristics in solving the optimal design problems of three conceptualised hydrogen-based micro-grids, as test-case systems. Accordingly, the obtained numeric simulation results using MATLAB indicate that some of the newly introduced meta-heuristics can play a key role in facilitating the successful, cost-effective development and implementation of hydrogen supply chain models. Notably, the moth-flame optimization algorithm is found capable of reducing the life-cycle costs of micro-grids by up to $6.5 \%$ as compared to the dragonfly algorithm.
\end{abstract}

Keywords: Optimal planning; Micro-grids; Meta-heuristics; Hydrogen technologies; Hydrogen economy; New Zealand.

Abbreviations: ABC, Artificial Bee Colony; ACO, Ant Colony Optimization; AI, Artificial Intelligence; ALO, Ant Lion Optimizer; BA, Bat Algorithm; BB-BC, Big Bang-Big Crunch; BBA, Binary Bat Algorithm; CSA, Cuckoo Search Algorithm; DA, Dragonfly Algorithm; DG, Distributed Generation; DPP, Discounted Payback Period; FA, Firefly Algorithm; GA, Genetic Algorithm; GOA, Grasshopper Optimization Algorithm; GSA, Gravitational Search Algorithm; GWO, Grey Wolf Optimizer; $\mathrm{H}_{2}$, Hydrogen; HABC-ACO, Hybrid ABC-ACO; HGA-PSO, Hybrid GAPSO; HSA, Harmony Search Algorithm; IHSA, Improved HSA; IRR, Internal Rate of Return; LCOE, Levelized Cost of Electricity; LCOH, Levelized Cost of Hydrogen; LPSP, Loss of Power Supply Probability; MFOA, Moth-Flame Optimization Algorithm; MG, Micro-Grid; MHP, Micro-Hydro Power; MPPT, Maximum Power Point Tracking; MSW, Municipal Solid Waste; MVO, Multi-Verse Optimizer; NFL, No-Free-Lunch; NIWA, National Institute of Water and Atmospheric Research; NP-hard, Non-deterministic Polynomial time-hard; NPC, Net Present Cost; PEM, Polymer Electrolyte Membrane; PI, Profitability Index; PSO, Particle Swarm Optimization; PV, Photovoltaic; RESs, Renewable Energy Sources; SA, Simulated Annealing; SCA, Sine-Cosine Algorithm; SC, Super-Capacitor; SSA, Salp Swarm Algorithm; TNPC, Total NPC; WEO, Water Evaporation Optimization; WT, Wind Turbine; WtE, Waste-toEnergy 


\section{Introduction}

Over the last three decades, research in artificial intelligence (AI) has developed a wide variety of techniques and methods that can be either adapted or utilised directly to solve complex problems in the energy sector (e.g. energy system investment planning, operation, as well as dynamic stability and control), which were thought to be unsolvable without several simplified assumptions [1]-[3]. Meta-heuristic optimization is a sub-discipline of AI that attempts to find the global optimal solutions to non-deterministic polynomial time-hard (NP-hard) problems, which are not amenable to exact mathematical optimization methods, through exploiting appropriate computational variations of natural systems [4].

In recent years, there has been growing interest in the concept of "smart energy systems" that expands on the concept of "smart grids" with the aim of exploiting the interplay between the electricity and transport sectors [5], [6]. Furthermore, it is envisioned that accelerating the development of a hydrogen economy - the utilisation of hydrogen as an energy carrier for power generation, fuelling the hydrogen vehicles, long-term energy storage, and long-distance green energy transportation - can play a pivotal role in realizing the zero-emissions, sustainable energy systems of tomorrow [7]-[9].

The optimal design and capacity planning problems of renewable and sustainable energy systems, including microgrids (MGs), nano-grids, energy hubs, virtual power plants, load aggregators, and so forth, is a complex combinational optimization problem with a non-smooth, non-convex objective function, as well as a variety of nonlinear constraints involved in its formulation. Accordingly, it has been classified as an NP-hard problem [10], [11].

Prior to the ground-breaking application of the particle swarm optimization (PSO) by Hakimi et al. [12], the exact mathematical optimization methods, such as linear programming [13], decomposition-based optimization [14], dynamic programming [15], mixed-integer linear programming [16], and mixed-integer nonlinear programming [17], were used to optimally design different forms of renewable energy systems. These methods are subject to some constraints on the continuity and derivability of the objective function, follow rigorous protocols, and often cannot track the dynamic changes. Following their seminal paper of 2007, several efforts have been made to harness the potential of the new AI-based meta-heuristic optimization techniques for making a positive impact on the quality of solutions either by: (1) development of the optimization algorithms that are well adapted to the class of problems at hand; or (2) putting the newly emerged meta-heuristics to the test using a trial-and-error mechanism, aiming at finding an algorithm, which improves the solution quality as compared to the algorithms previously found to be most effective in solving the considered problems.

As an example of the first class of the studies mentioned above, Mohandas et al. [18] have integrated the chaos theory into the artificial bee colony (ABC) algorithm, and by applying the proposed hybrid algorithm to the optimal equipment capacity planning problem of distributed generation (DG) units in a test-case distribution system, affirmed its superiority to the standard ABC algorithm in the context of MG design and planning. Derakhshan et al. [19] have improved the basic cuckoo search algorithm (CSA) by accommodating a crossover operator and adopted it to optimize the design variables of a grid-tied photovoltaic (PV)/wind turbine (WT)/battery test-case MG. Bahmani-Firouzi and Azizipanah-Abarghooee [20] have also enhanced the original bat algorithm (BA) by adding the mechanism that selfadaptively tunes the exploration and exploitation degrees of the optimization. The authors have demonstrated the higher performance of the improved BA over the basic BA, the PSO, and the genetic algorithm (GA) for the optimal sizing of a battery bank to be incorporated in an on-grid MG test-case system. Lorestani et al. [21] have put forward an enhanced variant of the PSO, named evolutionary-PSO, and considering a PV thermal/wind/battery/microturbine/boiler grid-independent MG have shown its primacy in approximating the globally optimum solution over the PSO, the GA, the differential evolution, and the harmony search algorithm (HSA) meta-heuristic optimization algorithms. As another example, Sheng and Zhang [22] have developed an enhanced binary bat algorithm (BBA) to optimize an MG optimal sizing problem. They have also shown the supremacy of their algorithm over the basic BBA, as well as the GA and the PSO. It is worthwhile noting that since the GA and PSO are two well-established algorithms in this research area, they are usually used as reference algorithms to examine the performance of other algorithms. In view of this, the GA and PSO are still popular among renewable energy system designers. For instance, Nagapurkar and Smith [23] and Hakimi et al. [24] have recently employed the GA and the PSO to optimally size the equipment of different configurations of fuel cell-supported MGs, respectively.

Putting the new meta-heuristics to the test has gained much more attention in the literature as compared to the adaption and enhancement of the standard meta-heuristics for the renewable energy system capacity planning purposes. Sharma et al. [25] have established the superiority of the grey wolf optimizer (GWO) over several other meta-heuristics, including the PSO and the GA, in solving the optimal sizing problem of an MG's battery energy storage system. 
Maleki and Pourfayaz [26] have proved the outperformance of the HSA over the simulated annealing (SA) algorithm, when applied to the optimal sizing problem of a PV/wind/diesel system. Singh et al. [27] have designed a cost-effective $\mathrm{PV} /$ wind/biomass $\mathrm{MG}$ using the $\mathrm{ABC}$ algorithm and validated its superior performance over the classic PSO. Fetanat and Khorasaninenejad [28] have affirmed the supremacy of the ant colony optimization (ACO) over the GA in solving the size optimization problem of a grid-independent PV/wind energy system. Kefayat et al. [29] go further and demonstrate the supremacy of the hybrid ABC-ACO (HABC-ACO) algorithm for the probabilistic sizing of distributed energy resources within a distribution system over the standard $\mathrm{ABC}$ and $\mathrm{ACO}$ algorithms. Bukar et al. [30] have proved the superior performance of the grasshopper optimization algorithm (GOA) over the CSA and the original PSO in optimizing the long-term investment planning problem of a stand-alone PV/wind/battery/diesel MG network. Tolba et al. [31] have shown the capability of the salp swarm algorithm (SSA) in better finding the global optima in renewable energy system optimal design problems as compared to the PSO, the GOA, and the gravitational search algorithm (GSA). Ali et al. [32] have put the ant lion optimizer (ALO) to the test for the optimal allocation and sizing of the renewable DG to be placed in a distribution network. The authors have highlighted that the ALO excels the PSO, the GA, the Big Bang-Big Crunch (BB-BC), and the CSA approaches. Furthermore, Ghorbani et al. [33] and Sharma et al. [34] have demonstrated the higher efficiency of the hybrid GA-PSO (HGA-PSO) compared to the original GA and PSO in the field of renewable energy system design using different MG test systems. Yang et al. [35] have confirmed the effectiveness of the teaching-learning-based optimization algorithm for the equipment capacity planning of MGs, whilst additionally providing a platform for the probabilistic modelling of the variability of the weather-dependent sources. Moreover, Gharibi and Askarzadeh [36] have adopted a multi-objective approach to jointly optimize the capacity of the equipment and the energy exchange of a grid-tied MG with its upstream power grid. Based on the numeric simulation results obtained by applying the multi-objective crow search algorithm to the derived optimization problem, they have demonstrated that the multi-objective crow search algorithm is not only computationally tractable when applied to their problem, but is also highly effective in finding the Pareto optimal frontier of the MG's minimized life-cycle cost, non-renewable energy fraction, and loss of power supply probability (LPSP).

The first systematic study on the efficiency comparison of a broad variety of meta-heuristics, when applied to the long-term infrastructure planning of a renewable energy system was carried out in 2018 by Peng et al. [37]. They have assessed the performance of nineteen meta-heuristics including single and hybrid algorithms in finding the optimum life-cycle cost of a solar/wind/battery renewable energy system that serves the purposes of water desalination. Although the results of their study are interesting in terms of emphasizing the need to continuously compare the accuracy of new optimizers, they did not take into account the state-of-the-art algorithms in their assessment. Furthermore, they predominantly dealt with the comparison of the new variants of well-established meta-heuristics, such as the modified PSO, the PSO based on constriction factor, the PSO using adaptive inertia weight, the improved HSA (IHSA), and the IHSA-based chaotic search.

The above review of the achievements in applying meta-heuristics to renewable and sustainable energy system planning problems identifies the lack of a comprehensive comparison among the investigated methods. Put differently, most of the studies have been limited to the comparison of the results obtained by applying a newly developed algorithm with those of some traditional meta-heuristics, as benchmark algorithms. It has not yet been established how the recently proposed meta-heuristics perform in comparison with each other. The no-free-lunch (NFL) theorem [38] also gives credence to these kinds of comparisons; according to which, there cannot exist a meta-heuristic that is unequivocally the best for solving all types of NP-hard optimization problems. Moreover, most studies have tended to focus on only one non-hydrogen-based renewable energy test-case system, when evaluating the performance of meta-heuristic optimization algorithms. The reader is referred to [39] for a detailed systematic review of the trends in the optimal equipment planning of hydrogen-based renewable and sustainable energy systems.

\subsection{Objectives and contributions of the study}

Based on the above premises, several meta-heuristics have been proposed in the literature to solve the optimal design and equipment capacity planning problems of MGs. However, there is still a need to continuously analyse their efficiencies with those of the newly emerged meta-heuristics - because, due to the stochastic nature of the metaheuristics, there is always the prospect that a new algorithm finds a better solution in the search space. In this respect, this paper compares the efficiencies of twenty meta-heuristic optimization algorithms based on three hydrogen-based MG test-case systems, proposed to provide clean electricity and transportation fuel for remote, rural, and semi-urban areas of New Zealand. The following algorithms are considered in this comparison study: the PSO [40], the GA [41], the HGA-PSO [42], the ABC algorithm [43], the ACO [44], the HABC-ACO [45], the ALO [46], the IHSA [47], the BB-BC algorithm [48], the moth-flame optimization algorithm (MFOA) [49], the sine-cosine algorithm (SCA) [50], 
the multi-verse optimizer (MVO) [51], the water evaporation optimization (WEO) [52], the GWO [53], the CSA [54], the SSA [55], the GOA [56], the dragonfly algorithm (DA) [57], the BA [58], and the firefly algorithm (FA) [59]. Table 1 highlights the merits and drawbacks of the aforementioned algorithms. Furthermore, an overview of the evaluated meta-heuristics is provided as Supplementary Material accompanying the paper (Additional File 1: An overview of the investigated meta-heuristic optimization algorithms).

Table 1. Strengths and weaknesses of the investigated meta-heuristics within the context of this study.

\begin{tabular}{|c|c|c|c|}
\hline Algorithm & Strengths & Weaknesses & Reference \\
\hline PSO & $\begin{array}{l}\text { - Fast convergence speed } \\
\text { - Robustness to the choice of parameters }\end{array}$ & - Premature convergence & {$[40]$} \\
\hline GA & $\begin{array}{l}\text { - Exchange of information between the } \\
\text { population to create new individuals }\end{array}$ & $\begin{array}{l}\text { - Highly susceptible to the choice of } \\
\text { the values of the operators }\end{array}$ & [41] \\
\hline HGA-PSO & $\begin{array}{l}\text { - Promoted diversity in the generation of } \\
\text { new individuals } \\
\text { - Improved exploration of the search } \\
\text { space }\end{array}$ & - Slow convergence rate & [42] \\
\hline $\mathrm{ABC}$ & $\begin{array}{l}\text { - Highly efficient in solving high- } \\
\text { dimensional problems }\end{array}$ & - Computationally demanding & [43] \\
\hline $\mathrm{ACO}$ & $\begin{array}{l}\text { - High exploration power due to } \\
\text { conducting parallel searches }\end{array}$ & $\begin{array}{l}\text { - Changes in the parametric } \\
\text { probability distribution used to } \\
\text { generate candidate solutions } \\
\text { throughout the iterations } \\
\text { - Poor performance when applied to } \\
\text { continuous optimization problems }\end{array}$ & [44] \\
\hline HABC-ACO & $\begin{array}{l}\text { - Enhanced efficiency in solving } \\
\text { continuous optimization problems }\end{array}$ & $\begin{array}{l}\text { - Excessive number of the required } \\
\text { function calls }\end{array}$ & [45] \\
\hline ALO & - Few parameters to tune & $\begin{array}{l}\text { - Highly sensitive to the choice of } \\
\text { control parameters }\end{array}$ & [46] \\
\hline IHSA & $\begin{array}{l}\text { - Fair balance between the exploration } \\
\text { and exploitation phases }\end{array}$ & $\begin{array}{l}\text { - The need to fine-tune the } \\
\text { parameters in different } \\
\text { applications }\end{array}$ & [47] \\
\hline BB-BC & - Easy implementation & $\begin{array}{l}\text { No trade-off between the } \\
\text { exploration and exploitation } \\
\text { potentials }\end{array}$ & [48] \\
\hline MFOA & $\begin{array}{l}\text { - Well-balanced exploration and } \\
\text { exploitation abilities }\end{array}$ & $\begin{array}{l}\text { - Highly vulnerable to changes in } \\
\text { the values of the parameters }\end{array}$ & [49] \\
\hline SCA & $\begin{array}{l}\text { - Guaranteed convergence to the near- } \\
\text { optima solution }\end{array}$ & - Computationally expensive & {$[50]$} \\
\hline MVO & $\begin{array}{l}\text { - Proven ability to avoid getting stuck in } \\
\text { local optima }\end{array}$ & $\begin{array}{l}\text { - Computationally intractable in } \\
\text { some applications }\end{array}$ & {$[51]$} \\
\hline WEO & - Low computational cost & - Stagnation in local optima & [52] \\
\hline GWO & $\begin{array}{l}\text { - Dynamic adjustment of control } \\
\text { parameters }\end{array}$ & - High computational complexity & [53] \\
\hline CSA & - Computationally-efficient & - Poor exploitation power & {$[54]$} \\
\hline SSA & $\begin{array}{l}\text { - Easy implementation stemming from its } \\
\text { simple concept }\end{array}$ & - Poor local search ability & {$[55]$} \\
\hline GOA & $\begin{array}{l}\text { - The need to adjust only a few } \\
\text { parameters }\end{array}$ & $\begin{array}{l}\text { - Excessive computational } \\
\text { overheads }\end{array}$ & {$[56]$} \\
\hline DA & $\begin{array}{l}\text { - Highly efficient in solving continuous } \\
\text { problems }\end{array}$ & $\begin{array}{l}\text { - Overflowing the } \\
\text { allowed search space limits as a }\end{array}$ & {$[57]$} \\
\hline
\end{tabular}




\begin{tabular}{|c|c|c|c|}
\hline & & $\begin{array}{l}\text { result of its relatively long step } \\
\text { lengths }\end{array}$ & \\
\hline BA & $\begin{array}{l}\text { - Providing very quick convergence at a } \\
\text { very initial stage by automatically } \\
\text { switching from the exploration to the } \\
\text { exploitation phase }\end{array}$ & - Rigorous theoretical foundation & {$[58]$} \\
\hline FA & $\begin{array}{l}\text { - Efficient in solving multi-modal } \\
\text { optimization problems }\end{array}$ & - Memory-less nature & [59] \\
\hline
\end{tabular}

The key contributions of this paper are:

1. One off-grid and two grid-connected battery-less, hydrogen-based MG architectures are proposed, which are first-of-their-kind in the renewable and sustainable energy systems literature. The proposed stand-alone system is projected to play a significant role in establishing a clean, resource-efficient, and climate-resilient energy economy for remote communities, while the grid-tied systems could pave the way for a cost-effective power system transition to integrate high levels of renewable generation and distributed energy resources.

2. A rule-based energy management strategy based on the queuing theory is developed for the operation of the hydrogen-backed MGs, which cost-efficiently integrates the hydrogen fuel cell-powered light-duty commuter vehicles, medium-duty vessels, heavy-duty tractors, and heavy-freight trucks into the conceptualised sustainable energy systems - which facilitates the take-up of low-carbon transport.

3. A statistics-based performance comparison framework is devised, which, for the first time, compares the efficiency of the meta-heuristic optimization algorithms in the MG design and planning context based on their success in nearing the global optima solutions, when applied to disparate MG configurations - either in terms of connection to an upstream grid or electricity generation/load demand profiles.

\section{Description of the suggested hydrogen-based MG test-case systems}

The proposed on- and off-grid hydrogen-based MGs aim at facilitating the deployment of a hydrogen economy in both the electricity and transport sectors, in line with the objectives of sustainable development. Accordingly, the configurations of the $100 \%$ renewable MGs are battery-less - either in terms of energy storage for a consistent power supply, or the integrated green vehicles. The rationale lies in the inefficiency of most of the commercially available battery types in terms of long-term energy storage, inability to track the very short-term variations of load, as well as the fact that they are not as environmentally friendly as they are often conceived due to the presence of toxic materials in their structures (which would be problematic after the end of their service lives) [60], [61].

\subsection{Micro-grid test-case system 1}

The first hydrogen-based MG, depicted in Fig. 1, is a grid-independent MG, which aims at satisfying the energy needs of isolated, remote island communities, whilst additionally providing a practical solution to manage their waste. It utilises some WTs for renewable power generation and includes a hybrid energy storage system consisting of supercapacitors (SCs) and a hydrogen-subsystem. A reactor-reformer system, as well as a waste-to-energy (WtE) plant, also, to some extent, contribute to the energy generation, whilst also serving the purposes of waste management. Moreover, the system is equipped with a hydrogen refuelling station, providing the fuel needed for hydrogen-powered vessels.

Municipal solid waste (MSW) is separated by the one-way sorting and separation system, which involves the two categories of MSW: organics, and non-organics. The organic fraction of the MSW, together with the agricultural biomass, is fed to the reactor-reformer system to produce hydrogen via methanation and steam reforming processes. The hydrogen produced by the reformer is then stored in a hydrogen tank, which is used as a resource to compensate for any lack of hydrogen. The non-organic fraction of the MSW is combusted in the WtE plant to generate electricity. 


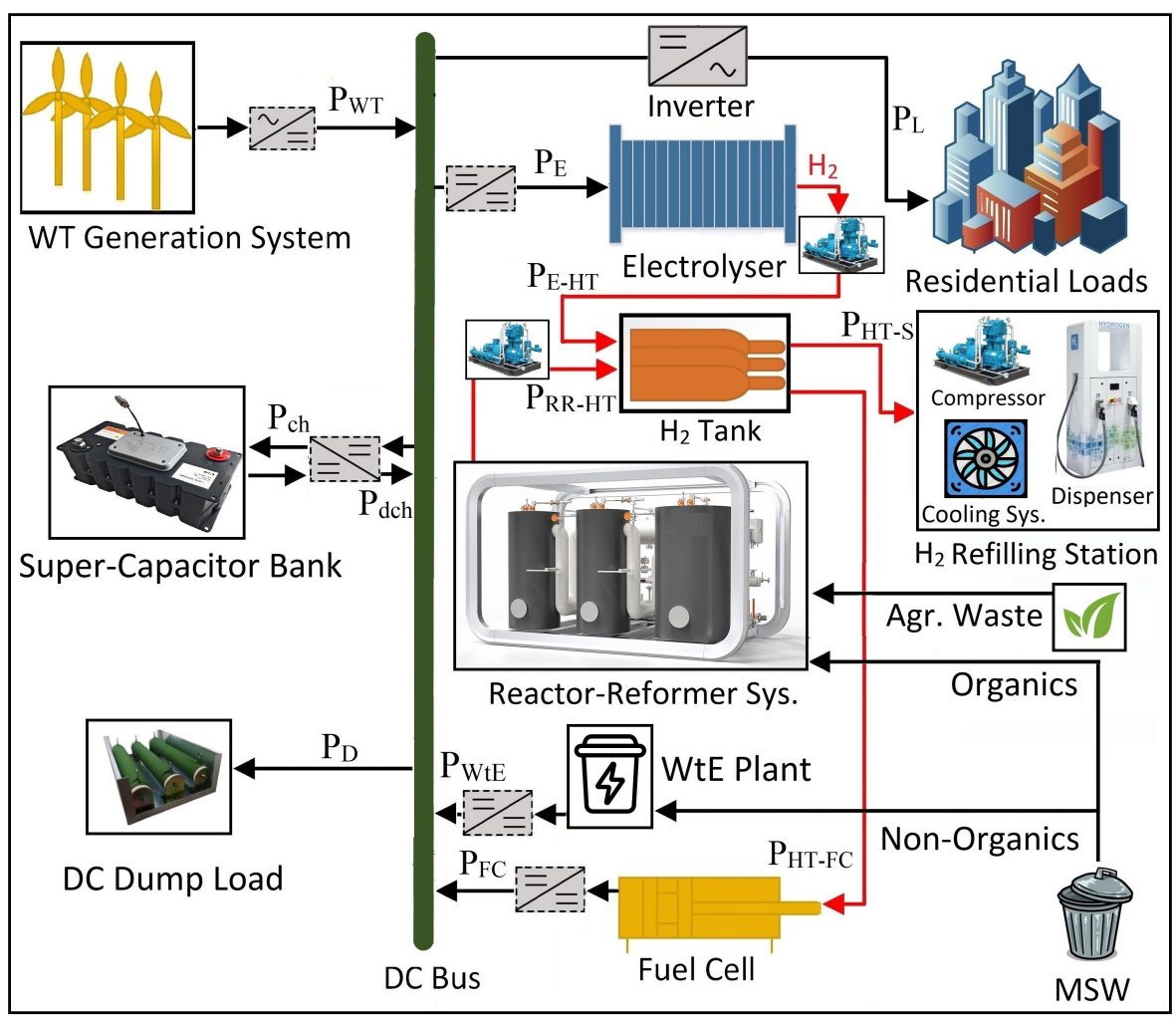

Fig. 1. Schematic diagram and power flow of the MG test-case system 1.

The mathematical models of the components of the MG test-case system 1 are expressed in the following sub-sections, together with instructions on the operation of the network.

\subsubsection{Wind turbine}

The Fuhrländer FL30 WT, whose output power-wind speed (at the hub height) characteristic curve is shown in Fig. 2 , is considered in this system. The WT has a rated power of $30 \mathrm{~kW} \mathrm{AC}$ and a hub altitude of $27 \mathrm{~m} \mathrm{[62].}$

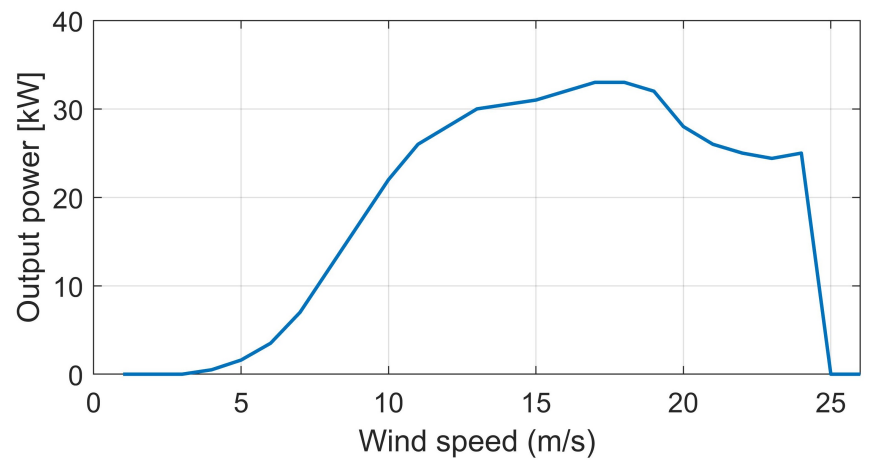

Fig. 2. Characteristic curve of the FL30 WT [62].

In order to normalize the wind speed profile, measured at the height of $h_{r e f}$, to the hub height of the WT under study, $h$, the following equation can be used [63]:

$$
V_{h}=V_{\text {ref }} \times\left(\frac{h}{h_{\text {ref }}}\right)^{\gamma}
$$


where $V_{\text {ref }}$ represents the reference speed recorded at the height of $h_{r e f}$ and $\gamma$ is a number in the range [0.1, 0.25] that reflects the status of the terrain on which the turbine is going to be installed. The value of this parameter is 0.25 for the non-flat, tree-covered land areas, considered in this study as case study sites.

\subsubsection{Waste-to-energy plant}

The output power of the considered generic WtE plant at time step $t$ can be calculated by the following equation [64]:

$$
P_{W t E}(t)=\frac{H H V_{N O W} \times \eta_{W t E} \times M_{N O W}(t)}{\Delta t}
$$

where $\eta_{W t E}$ is the efficiency of the WtE plant (i.e. $\left.18 \%\right), H H V_{N O W}$ stands for the higher heating value of the nonorganic fraction of the MSW (i.e. $35.7 \mathrm{MJ} / \mathrm{kg}$ ), $M_{N O W}(t)$ is the amount of non-organics fed to the WtE plant at time step $t$, and $\Delta t$ is the length of each time step (i.e. $1 \mathrm{~h}$ ).

\subsubsection{Hybrid energy storage system}

A hybrid energy storage system consisting of an SC bank and a hydrogen sub-system - an electrolyser, a reactorreformer system, a hydrogen tank, and a fuel cell - is considered to compensate for the intermittency of the renewable power generation technologies and the variations in energy demand. The hybrid energy storage medium is operated by the strategy proposed by Akram et al. [65] for the operation of a hybrid battery-SC energy storage system. In this respect, a low-pass energy filter first divides the energy shortfall/excess into the low- and high-frequency components, which are then supplied/absorbed by the hydrogen sub-system and SCs, respectively. The objective of such hybridization is to allow for leveraging the high power/energy density capability of SCs/hydrogen subsystem, thereby improving the resilience of the system to both the sudden and gradual changes in load demand and/or output powers from the weather-driven power generators.

\subsubsection{Super-capacitors}

The MAXWELL EDLC SC modules with a capacity of $3.23 \mathrm{Wh}$ handle the high-frequency component of the energy shortfall/excess [66]. The amount of energy stored in the SC bank can be expressed by the following equation [67]:

$$
E_{S C}(t)=E_{S C}(t-1)+\left(P_{c h}(t)-\frac{P_{d c h}(t)}{\eta_{S C}}\right) \times \Delta t,
$$

where $\eta_{S C}$ is the round-trip efficiency of the SC bank (i.e. 95\%); with $P_{c h}(t)$ and $P_{d c h}(t)$ representing the charging and discharging powers of the $\mathrm{SC}$ bank at time step $t$, respectively.

The energy content of the SC bank is constrained using Eq. (4) [67].

$$
E_{S C, \min } \leq E_{S C}(t) \leq E_{S C, \max }
$$

where $E_{S C, \min }$ and $E_{S C, \max }$ are the minimum and maximum allowable storage capacities of the SC bank that are determined as [66]:

$$
\begin{aligned}
& E_{S C, \text { min }}=\left(0.5 \times N_{S C} \times U_{S C, \text { min }}^{2}\right) /\left(3.6 \times 10^{6}\right), \\
& E_{S C, \text { max }}=\left(0.5 \times N_{S C} \times U_{S C, \text { max }}^{2}\right) /\left(3.6 \times 10^{6}\right),
\end{aligned}
$$

where $N_{S C}$ is the optimal number of $\mathrm{SCs} ; U_{S C, \min }$ (i.e. $0.8 \mathrm{~V}$ ) and $U_{S C, \max }$ (i.e. $2.7 \mathrm{~V}$ ) are the minimum and maximum allowable voltage levels of the SC modules, respectively; with the numerical value of $3.6 \times 10^{6}$ converting the unit of measurement from $\mathrm{J}$ to $\mathrm{kWh}$.

\subsubsection{Hydrogen sub-system}

The generic hydrogen sub-system conceptualised in this paper, consists of a polymer electrolyte membrane (PEM) electrolyser, an anaerobic reactor-reformer system, an intermediary-pressure compressor, a hydrogen tank, as well as a stationary PEM fuel cell. All the components of the hydrogen sub-system are generic products, whose technoeconomic specifications are available in [68]-[70]. 
The PEM electrolyser dissociates water molecules into oxygen and hydrogen atoms in the gas phase. The hydrogen power delivered from the electrolyser to the tank can be calculated as [67]:

$$
P_{E-H T}(t)=P_{E}(t) \times \eta_{E},
$$

where $\eta_{E}$ is the total efficiency of the electrolyser unit, i.e. $60 \%$, and $P_{E}(t)$ is the power consumed by the electrolyser at time step $t$. An intermediary-pressure compressor, shown in Fig. 1, is utilised to compress the hydrogen produced by the electrolyser at around 1.2 bar pressure to around 20 bar in order to reduce the volume it occupies.

The other hydrogen generator element in this layout is a united anaerobic reactor-reformer system that converts the organic fraction of the MSW, as well as the agricultural residues, into the hydrogen, which is also pressurized by a compressor before being reserved in the tank.

The output hydrogen power of the united reactor-reformer system, conceptualised by Hakimi and Moghaddas-Tafreshi [71], which has a waste-to-hydrogen efficiency of $4.54 \%$ and utilises a MAHLER reformer can be calculated by [71]:

$$
P_{R R-H T}(t)=0.0454 \times H H V_{H 2} \times M_{O W-B}(t),
$$

where $H H V_{H 2}$ is the higher heating value of the hydrogen (i.e. $39.7 \mathrm{kWh} / \mathrm{kg}$ ) and $M_{O W-B}(t)$ is the aggregate amount of organic MSW and agricultural waste fed to the reactor-reformer unit at time step $t$.

The level of hydrogen energy stored in the tank at each time step can be calculated by the following equation [67]:

$$
E_{H T}(t)=E_{H T}(t-1)+\left(P_{E-H T}(t)+P_{R R-H T}(t)-\frac{\left(P_{H T-F C}(t)+P_{H T-S}(t)\right)}{\eta_{\text {tank }}}\right) \times \Delta t,
$$

where $P_{H T-F C}(t)$ is the delivered hydrogen power from the storage tank to the fuel cell at time step $t ; P_{H T-S}(t)$ is the delivered hydrogen power from the hydrogen reservoir to the refilling station at time step $t$; and $\eta_{\text {tank }}$ is the roundtrip efficiency of the tank, i.e. $95 \%$.

Accordingly, the mass of stored hydrogen at each time step can be calculated as follows [71]:

$$
m_{H T}(t)=\frac{E_{H T}(t)}{H H V_{H 2}}
$$

The constraints imposed by Eq. (11) leverage the facts that the energy stored in the tank cannot exceed its nominal capacity and some fraction of the hydrogen energy cannot be released due to some concerns associated with the pressure drop [72].

$$
E_{H T, \min } \leq E_{H T}(t) \leq E_{H T, \max }
$$

where $E_{H T, \min }$ and $E_{H T, \max }$ are the minimum and maximum allowable storage capacities of the reservoir, respectively. In this study, $E_{H T, \min }$ is set as $5 \%$ of $E_{H T, \max }[73]$.

Furthermore, the output power of the stationary fuel cell at time step $t$ can be calculated by [72]:

$$
P_{F C}(t)=P_{H T-F C}(t) \times \eta_{F C},
$$

where $\eta_{F C}$ is the electrical efficiency of the fuel cell, i.e. $40 \%$.

\subsubsection{Hydrogen refuelling station}

The considered hydrogen refilling station in this study, is mainly composed of a high-pressure compressor (i.e. 20 to $350 \mathrm{bar}$ ), a cooling system, and a dispenser to deliver the fuel to the hydrogen fuel cell-powered vehicles or vessels via nozzles. The output hydrogen power of the station $\left(\mathrm{kg} \mathrm{H}_{2} / \mathrm{h}\right)$ is employed in this paper as a decision variable to evaluate the optimal capacity of the station. The hydrogen refilling station conceptualised in this study is inspired by the schemes proposed in [74]-[78] and has an efficiency $\left(\eta_{S}\right)$ of $95 \%$.

\subsubsection{Hydrogen-powered vessels}

Since the MG test system 1 is particularly designed and proposed for remote, island communities, the hydrogen fuel cell-powered passenger ferries are integrated within the system through utilising the considered hydrogen station. In this regard, the Hydrogenesis Passenger Ferry is selected as the eco-friendly, hydrogen-powered boat. The ferry is 
powered by four $12 \mathrm{~kW}$ fuel cells that operate at the voltage of $48 \mathrm{~V}$. Also, this 14-seater ferry is equipped with a purpose-built tank, which stores hydrogen at the pressure of 350 bar [79].

\subsubsection{Inverter}

The generic DC/AC inverter, tying the residential electrical loads to the MG's network, is modelled by its efficiency, $\eta_{I n v}$, meaning that the actual load that must be satisfied is $\left(1 / \eta_{I n v}\right)$-times the imposed load on the MG. An efficiency of $90 \%$ is considered in this analysis for the inverter.

\subsubsection{Operational strategy}

The cycle-charging energy dispatch scheme is employed in this study to operate the MGs, which is electrically-driven and absorbs/supplies the excess/shortage of renewable power by the hybrid energy storage system, illustrated in subsection 2.1.3. When the hydrogen tank/SC bank is fully charged or the amount of low-/high-frequency component of the excess power is greater than the capacity of the electrolyser/SC bank, then the surplus power is dumped through a DC dump load. On the other hand, when the energy storage system is not able to afford the power shortfall, a loadshedding scheme ensures the stability of the system, which increases the unreliability of power supply. Moreover, it is assumed that the supply of hydrogen is guaranteed by setting a separate reliability constraint, which is illustrated in Section 3.

\subsection{Micro-grid test-case system 2}

The second test system, shown in Fig. 3, is a notional grid-tied hydrogen-based MG, proposed to provide green electricity and hydrogen as a transportation fuel for semi-urban communities.

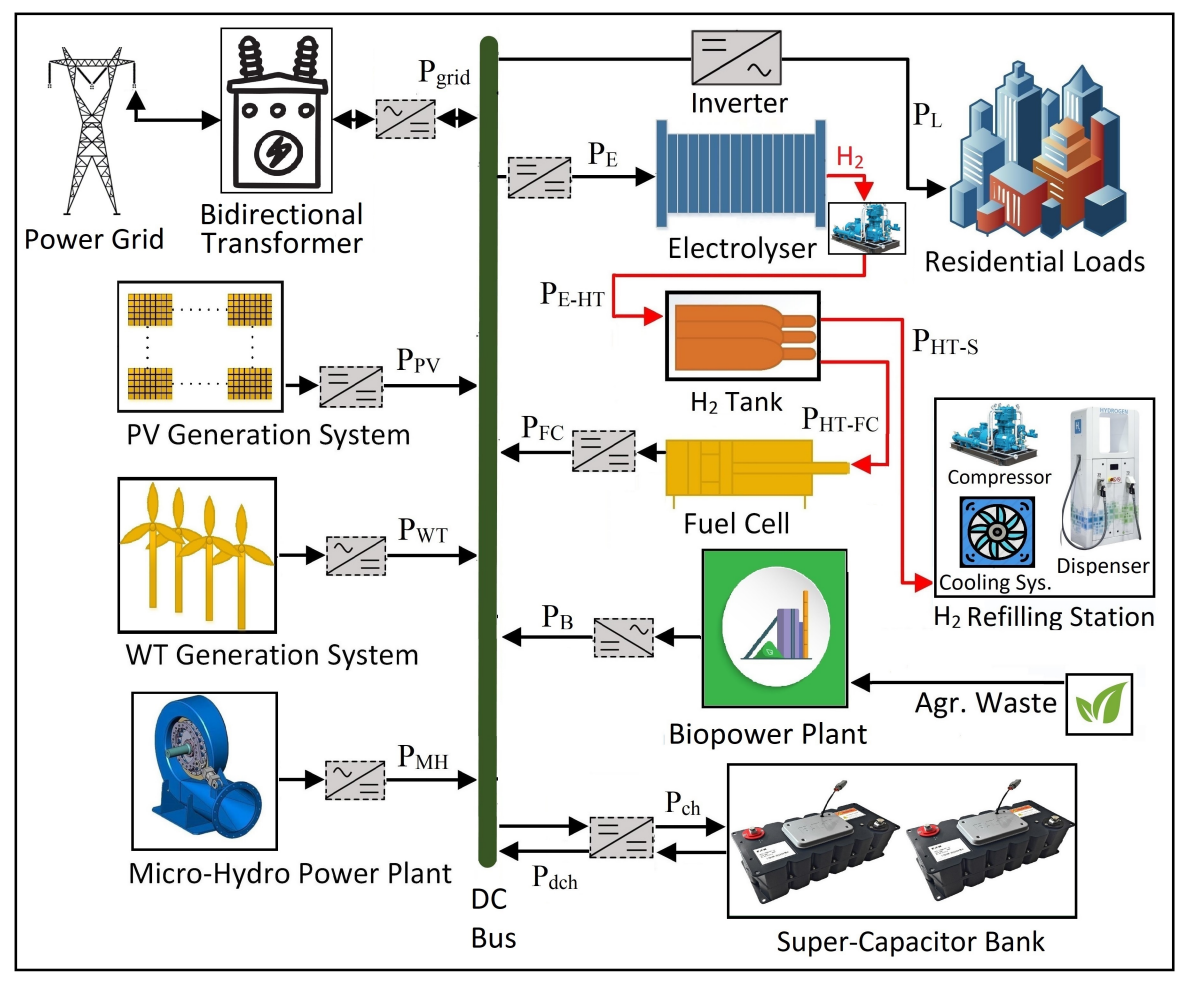

Fig. 3. Schematic diagram and power flow of the MG test-case system 2.

The mathematical description of the functions of the components, employed within the MG test-case system 2, is presented in the following paragraphs, along with some information on the operation of the system.

The mathematical models of the hybrid energy storage system (without a reactor-reformer system), the residential loads' inverter, as well as the hydrogen refuelling station are developed in a similar way as outlined for system 1. In this layout, the electrolytic hydrogen production using renewable energy sources (RESs) is the only planned mechanism to provide the hydrogen demands of the system. 


\subsubsection{Micro-hydro power plant}

The Natel FreeJet FJ-7A micro-hydro power (MHP) plant is adopted in the second MG's structure to generate power on a run-of-the-river scheme. The plant has a rated power of $49 \mathrm{~kW}$ and its output power can be calculated by Eq. (13) [80].

$$
P_{M H}(t)=N_{M H} \times \rho \times h \times g \times \eta_{M H} \times \frac{F(t)}{1000},
$$

where $N_{M H}$ is the calculated optimal number of MHPs, $\rho$ represents the water density (i.e. $1000 \mathrm{~kg} / \mathrm{m}^{3}$ ), $h$ denotes the gross head height (i.e. $7 \mathrm{~m}$ ), $g$ represents the acceleration of gravity (i.e. $\left.9.81 \mathrm{~m} / \mathrm{s}^{2}\right), \eta_{M H}$ is the overall efficiency of the plant (i.e. $55 \%$ ), and $F(t)$ is the hourly streamflow $\left(\mathrm{m}^{3} / \mathrm{s}\right)$.

\subsubsection{Wind turbine}

The Fuhrländer FL100 WT, whose characteristic curve (provided by the manufacturer) is shown in Fig. 4, is considered in the MG test-case system 2. The WT has a rated power of $100 \mathrm{~kW} \mathrm{AC}$ and a hub altitude of $38 \mathrm{~m} \mathrm{[62].}$

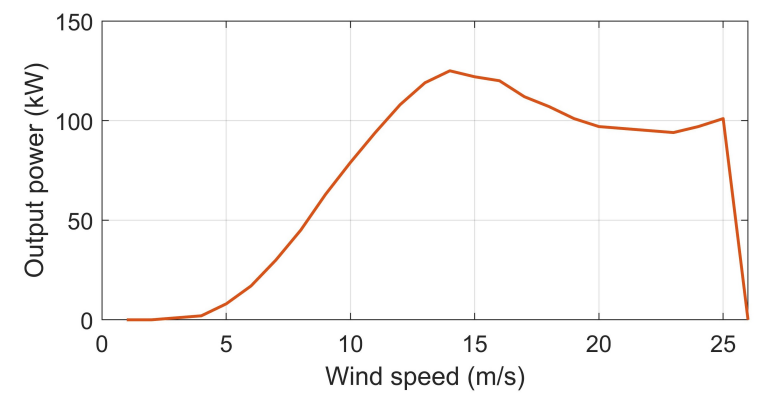

\subsubsection{Photovoltaic panel}

Fig. 4. Characteristic curve of the FL100 WT [62].

The Canadian Solar CS6U-325P PV panel is adopted in this test-case system [68]. It is of the polycrystalline type and has a rated power of $325 \mathrm{~W}$. The output power of the PV generation system $(\mathrm{kW})$ at time step $t$ can be calculated using Eq. (14) [33].

$$
P_{P V}(t)=N_{P V} \times \eta_{g} \times A_{m} \times G(t),
$$

where $N_{P V}$ indicates the optimal number of PV panels, $\eta_{g}$ is the overall PV generator's efficiency (i.e. $15 \%$ ), $A_{m}$ identifies the area of each panel (i.e. $1.92 \mathrm{~m}^{2}$ ), and $G(t)$ represents the total solar irradiance on the tilted planes of the $\mathrm{PV}$ panels $\left(\mathrm{kW} / \mathrm{m}^{2}\right)$ at time step $t$.

\subsubsection{Maximum power point tracking}

A maximum power point tracking (MPPT) apparatus is employed to exploit the maximum output power of the PV generator at each level of irradiance. The function of the tracker can be mathematically modelled by Eq. (15) [81].

$$
P_{P V, M P P T}(t)=P_{P V}(t) \times\left(1-k_{T}\left(T_{a}(t)-T_{p, r e f}\right)\right),
$$

where $k_{T}$ denotes the temperature coefficient of the apparatus (i.e. $\left.0.5 \%\right), T_{a}(t)$ is the ambient temperature at time step $t\left({ }^{\circ} \mathrm{C}\right)$, and $T_{p, r e f}$ represents the panels' temperature at the standard (reference) condition, i.e. $25^{\circ} \mathrm{C}$.

\subsubsection{Biomass power plant}

The notional biomass power plant considered in this analysis incorporates an anaerobic digestion reactor, a steam methane reformer, an air separation unit, and an internal combustion engine. The anaerobic digestion reactor utilises the low-grade agricultural biomass to produce methane gas. The steam methane reformer uses the methane gas produced by the reactor to produce pure hydrogen gas at high temperatures between 900 and $1000^{\circ} \mathrm{C}$. Finally, the hydrogen is burned in pure oxygen, provided by an air separation plant, in the internal combustion engine to generate 
clean electricity - water is the only product of the combustion of hydrogen in oxygen. The overall waste $(\mathrm{kg})$ to power $(\mathrm{kW})$ efficiency of the conceptualised biomass power plant is $3.47 \%$ [71], [82].

\subsubsection{Upstream grid}

The second MG is coupled to an upstream power grid via a bidirectional transformer. It is assumed that the grid can compensate for any lack of power generation within the MG, as an infinite-bus. On the other hand, it absorbs any surplus power generated by renewable technologies, thereby eliminating the need for a DC dump load. For the energy transactions, it is assumed that the grid sells the power to the $\mathrm{MG}$ at a flat rate of $\$ 0.21 / \mathrm{kWh}$, in New Zealand currency, while the feed-in tariff is set at $\$ 0.13 / \mathrm{kWh}[83]$.

The cost of power exchange with the upstream power grid at each time step can be calculated as follows [84]:

$$
\operatorname{cost}_{\text {grid }}(t)= \pm P_{\text {grid }}(t) \times \pi_{e x} \times \Delta t,
$$

where $P_{\text {grid }}(t)$ denotes MG's exchanged power with the upstream grid at time step $t$ and $\pi_{e x}$ is the price of power exchange per kWh. It is worth noting that a positive value of $P_{\text {grid }}$ represents a purchasing power from the upstream power grid and a negative value represents any sold power to the upstream power grid.

The power exchange with the upstream grid is subject to the following constraint [84]:

$$
P_{\text {grid }}(t) \leq P_{\text {grid,max }}
$$

where $P_{\text {grid,max }}$ is the maximum permissible power exchange of the MG with the upstream grid. This constraint represents the empirical limitations on the network. In other words, the maximum value represents the practical upper constraint on the size of the transformer coupling the MG to the upstream grid.

Hence, the value of $P_{\text {grid,max }}$ is considered as one of the decision variables, which implicitly identifies the size of the required bidirectional transformer. In this respect, the solid-state transformer, proposed by Qin and Kimball [85], is adopted in this study. It utilises four-quadrant switch cells to allow bidirectional power flow and controls the power via a phase shift mechanism between two active H-bridges. The nominal efficiency of this transformer is expected to be $93 \%$. The capacity of the transformer is going to be determined in kVA. However, for the sake of simplicity, the power factor (i.e. defined as active power in $\mathrm{kW}$ divided by apparent power in $\mathrm{kVA}$ ) is assumed to be constant and equal to 0.95 .

\subsubsection{Light-duty hydrogen-powered fuel cell vehicles}

Since the MG test-case 2 is particularly designed for semi-urban areas, a fleet of light-duty hydrogen fuel cell-powered vehicles is integrated into the system via utilising the refuelling infrastructure. Accordingly, the Rasa, manufactured by Riversimple, is selected as the light-duty fuel cell vehicle. It contains an $8.5 \mathrm{~kW}$ fuel cell-powered electric motor and a $1.5 \mathrm{~kg}$ hydrogen tank that stores the hydrogen at $350 \mathrm{bar}$. This is unlike most other light-duty fuel cell vehicles that store the hydrogen at 700 bar, which leads to the higher rates of energy use as well as the need for the more expensive filling stations [86].

\subsubsection{Operational strategy}

As per the first test-case MG system's operational strategy (sub-section 2.1.6), the cycle-charging energy dispatch mechanism is adopted to operate the second MG. The only difference is that when the hybrid energy storage system is not able to supply/absorb the energy shortfall/excess, the upstream grid takes the responsibility to inject/withdraw the requested/surplus energy, instead of load shedding/energy spillage. Nevertheless, if the requested power violates the constraint in Eq. (17), still, load-shedding/energy spillage would be necessary.

\subsection{Micro-grid test-case system 3}

The third test-case system, schematically diagrammed in Fig. 5, is a grid-connected MG, conceptually proposed to improve the energy self-sufficiency of rural communities that currently have access to the main grid, and thereby enhance their resilience to the upstream network outages. It also provides a platform to manage their municipal solid and agricultural waste. 


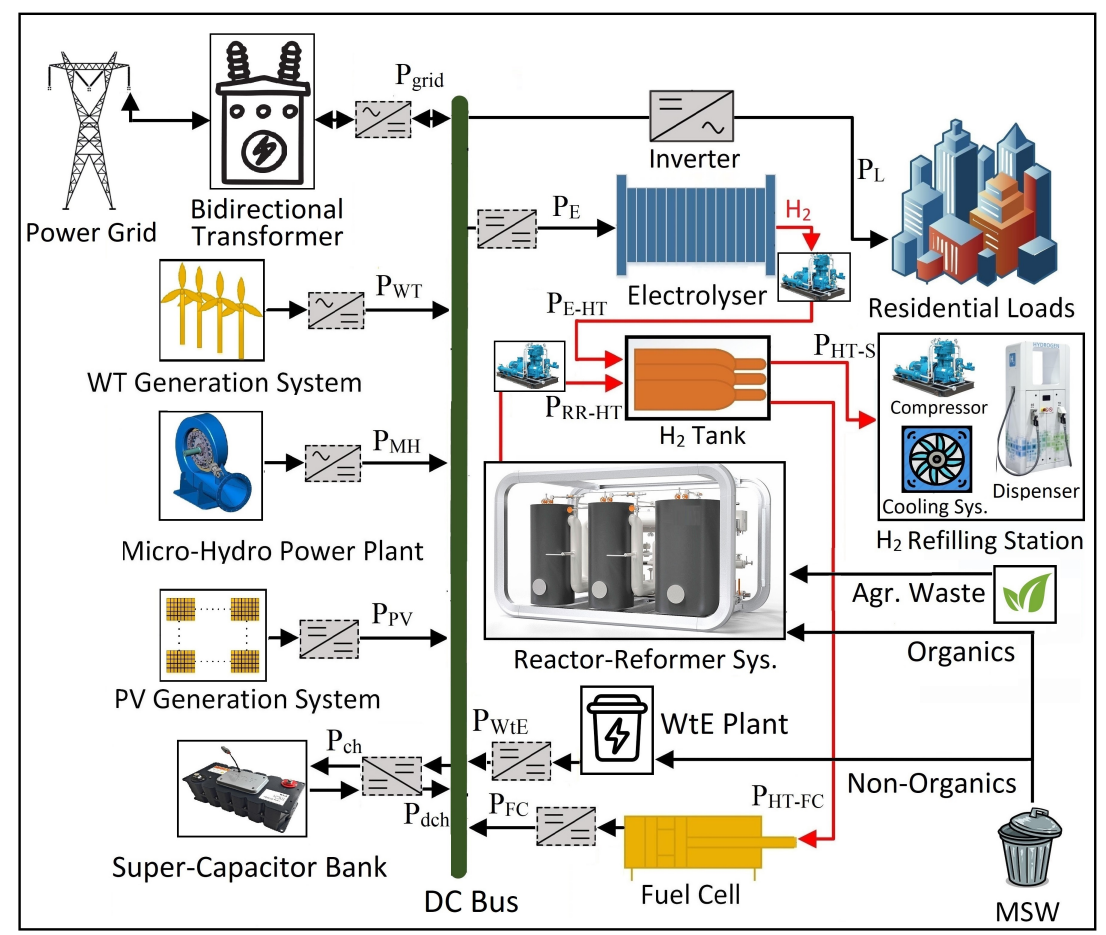

Fig. 5. Schematic diagram and power flow of the MG test-case system 3.

The mathematical models of the hybrid energy storage system, the WtE plant, the residential loads' inverter, and the hydrogen refuelling station are the same as those outlined for the MG test-case 1, while the mathematical models of the upstream grid, as well as the PV and MHP generators, are the same as those illustrated for the MG test-case 2. The WT generation system in this scheme consists of both the FL30 and FL100 WTs, which are respectively modelled in sub-sections 2.1.1 and 2.2.2. Furthermore, the network is operated in a similar manner as outlined for system 2.

\subsubsection{Heavy-duty hydrogen-powered fuel cell vehicles}

For the third MG system, hydrogen fuel cell-powered trucks and tractors are considered as hydrogen loads. Accordingly, Hyundai's heavy-duty fuel cell-electric truck and New Holland's NH2 fuel cell-powered tractor are considered as the heavy-duty hydrogen-powered vehicles that utilise the station. The considered truck and tractor respectively hold 32.86 and $8.2 \mathrm{~kg}$ of gaseous hydrogen in the type IV carbon composite-based tanks at a pressure of 350 bar [87], [88].

\section{Life-cycle cost projection methodology}

In order to project the minimized whole-life costs of installing the considered MG projects, whilst satisfying the requirements of electricity and hydrogen fuel supply over their life spans, a methodology is developed in this section. The proposed methodology utilises the concepts of the net present cost (NPC) and the LPSP respectively for modelling the total life-cycle costs and measuring the reliability of these systems. The devised methodology also determines the optimal size of the equipment included in the configurations suggested for the test-case MGs.

\subsection{Model reduction}

In order to alleviate the computational intensiveness of simulations, we adopt the idea proposed by Mavrotas et al. [89] to compress the hourly-basis, year-round historical input data (i.e. load demand and output powers from RESs) to the monthly averaged daily (24-h) profiles.

\subsection{Reliability assessment}


In order to evaluate the reliability of power and transportation fuel supply in the conceptualised MG schemes, the LPSP index is employed in this study, which can be defined by Eq. (18) [90].

$$
L P S P=100 \times \frac{\left.\sum_{i=1}^{N} \operatorname{hours}\left[P_{\text {supp }}(i)<P_{d e m}(i)\right)\right]}{N},
$$

where $P_{\text {supp }}$ denotes the supplied electric/hydrogen power, $P_{\text {dem }}$ represents the demand for electricity/hydrogen, and $N$ indicates the total number of hours considered in the operational timeframe.

An LPSP equal to zero means that the consumer electricity and transportation fuel demand will always be satisfied, while a value equal to one means that they will never be met. Two separate LPSP indices are considered in this study for the supply of electricity and hydrogen, whose desired values are set at zero per cent.

\subsection{Objective functions}

The objective functions are derived based on the whole-life costs of the MGs' equipment, utilising the NPC concept. The NPC of each component can be obtained by [12]:

$$
N P C=N \times\left(C C+R C \times K+O \& M \times \frac{1}{C R F(d, R)}-S V\right),
$$

where $N$ is the optimal size (capacity/number) of the component; $C C, R C$, and $O \& M$ denote the capital, replacement, and operation and maintenance costs, respectively; $S V$ represents the salvage value (the residual value of the element at the end of the projected lifespan of the project) that can be calculated by Eq. (20); and $C R F$ and $K$ respectively denote the capital recovery factor and the single payment present worth, which can be obtained by Eqs. (21)-(23) [91]. The variables representing the optimal sizes of the components (that are considered to be the design (decision) variables of the problem) could be of the type either discrete or continuous (depending on the nature of the components), where discrete/continuous variables are assigned to the components, whose optimum numbers/capacities are under question; thereby, intensifying the optimization problem's complexity.

$$
\begin{gathered}
S V=R C \times \frac{L-\left(R-L \times\left\lfloor\frac{R}{L}\right\rfloor\right)}{L}, \\
C R F(d, R)=\frac{d(1+d)^{R}}{(1+d)^{R}-1}, \\
K=\sum_{n=1}^{Y} \frac{1}{(1+d)^{L \times n}}, \\
Y=\left\{\begin{array}{l}
\left\lfloor\frac{R}{L}\right\rfloor-1 ; \quad \text { if } R \text { is an integer multiple of } L, \\
\left\lfloor\frac{R}{L}\right\rfloor ; \quad \text { if } R \text { is not an integer multiple of } L,
\end{array}\right.
\end{gathered}
$$

where $d$ is the real interest rate per annum, which is obtained by Eq. (24) [91]; $R$ is the projected lifespan of the MG network (year); and $L$ is the expected lifetime of each component (year). In this study, $R$ is considered to be 20 years.

$$
d=\frac{d^{\prime}-f}{1+f}
$$

where $d^{\prime}$ denotes the nominal interest rate (i.e. the rate at which funds can be borrowed from the banks) and $f$ represents the expected annual inflation rate. Currently, the nominal interest and inflation rates in New Zealand are $16.19 \%$ (i.e. calculated by averaging the rates offered by different banks within the country for businesses) [92] and $1.5 \%$ (i.e. reported by The Treasury New Zealand) [93], respectively. Note that in this analysis, we have taken a conservative approach and considered the interest rates associated with the business overdraft facilities provided by banks, instead of their long-term business loan services, in calculating the nominal interest rate. The reported nominal 
interest rate does not consider any policy support mechanisms to assist investors with these renewable energy system projects.

As shown in Eq. (25), the total NPCs (TNPCs) of the systems can be expressed in an annualized form by multiplying them by the capital recovery factor [94].

$$
T N P C_{a n n}=\operatorname{CRF}(d, R) \times T N P C .
$$

Then, the MGs' levelized costs of energy $(\$ / \mathrm{kWh})$ can be calculated by dividing their annualized TNPCs by the aggregate electrical and hydrogen energy $(\mathrm{kWh})$ they serve to the customers over their projected lifespans [95]. The levelized costs of energy can be further divided into the levelized cost of electricity (LCOE) and levelized cost of hydrogen $(\mathrm{LCOH})$, leveraging the fact that the costs associated with the components that fulfil no functions in supplying each energy type should not be included in its levelized cost calculation.

Based on the above premises, the objective functions of the established MGs that must be minimized by the metaheuristics under investigation, are introduced in the following sub-sections.

\subsubsection{Micro-grid 1}

The objective function, employed to economically design the first MG, is defined as follows:

$$
T N P C_{1}=N P C_{W T 1}+N P C_{W t E}+N P C_{E}+N P C_{H T}+N P C_{F C}+N P C_{R R}+N P C_{S C}+N P C_{S}+N P C_{I}
$$

where $N P C_{W T 1}, N P C_{W t E}, N P C_{E}, N P C_{H T}, N P C_{F C}, N P C_{R R}, N P C_{S C}, N P C_{S}$, and $N P C_{I}$ respectively represent the NPCs of the FL30 WTs, the WtE plant, the electrolyser, the hydrogen tank, the fuel cell, the reformer-reactor system, supercapacitor modules, the refuelling station, and the inverter.

\subsubsection{Micro-grid 2}

The second MG's objective function is contained in Eq. (27).

$$
\begin{gathered}
T N P C_{2}=N P C_{P V}+N P C_{W T 2}+N P C_{M H P}+N P C_{B}+N P C_{E}+N P C_{H T}+N P C_{F C}+N P C_{T}+N P C_{S C}+N P C_{S} \\
+N P C_{I}+N P C_{\text {buy }}+N P C_{\text {sell }},
\end{gathered}
$$

where $N P C_{P V}, N P C_{W T 2}, N P C_{M H P}, N P C_{B}$, and $N P C_{T}$ respectively denote the NPCs of the PV generator, FL100 WTs, the MHP plant, the biomass power plant, and the transformer; while $N P C_{\text {buy }}$ and $N P C_{\text {sell }}$ respectively represent the NPCs associated with buying/selling electricity from/to the upstream power network, which can be calculated by the following equations [96]:

$$
\begin{aligned}
& N P C_{\text {buy }}=\pi_{\text {buy }} \times \frac{1}{\operatorname{CRF}(d, R)} \times \sum_{t=1}^{N} P_{\text {grid }}(t), \\
& N P C_{\text {sell }}=F i T \times \frac{1}{C R F(d, R)} \times \sum_{t=1}^{N} P_{\text {grid }}(t),
\end{aligned}
$$

where $\pi_{b u y}$ and FiT denote the price of buying electricity from the upstream network and the feed-in-tariff, respectively.

It is worthwhile noting that at each time step, $P_{\text {grid }}$ can be in one of three states: purchasing power (positive values), selling power (negative values), or neutral (zero values). Two separate binary variables are employed to restrict the positive and negative values of $P_{\text {grid }}$ to be only used in Eqs. (28) and (29), respectively. It is also obvious that the objective function presented in Eq. (27) is defined algebraically (note that the quantity of $N P C_{\text {sell }}$ is always negative). Moreover, as stated earlier, $\pi_{\text {buy }}$ and FiT are set at the flat rates of $\$ 0.21 / \mathrm{kWh}$ and $\$ 0.13 / \mathrm{kWh}$, in New Zealand currency, respectively, in compliance with average prices in New Zealand's residential electricity market [83].

\subsubsection{Micro-grid 3}


The objective function related to the optimal equipment capacity planning of MG 3 is derived as follows:

$$
\begin{gathered}
T N P C_{3}=N P C_{P V}+N P C_{W T 1}+N P C_{W T 2}+N P C_{M H P}+N P C_{W t E}+N P C_{T}+N P C_{E}+N P C_{H T}+N P C_{F C} \\
+N P C_{R R}+N P C_{S C}+N P C_{S}+N P C_{I}+N P C_{\text {buy }}+N P C_{\text {sell }} .
\end{gathered}
$$

\subsection{Constraints}

The minimization of the above-mentioned objective functions is undertaken subject to some constraints on the operation of the equipment as well as the planning of the systems. The constraints at the operation level of the optimization problem are those expressed in Eqs. (4), (11), and (17). There are three types of constraints at the planning phase of the optimization problem: (1) those related to the reliability of energy supply, which ensure a consistent supply of electricity and hydrogen; (2) those related to the equality of the initial and final energy contents of the hydrogen tank, as well as the SC bank, in one operational timeframe, and (3) those related to the upper bounds of the non-negative decision variables (sizes of the components) that are set as follows:

$N_{P V} \leq 9,000 ; N_{W T 1} \leq 200 ; N_{W T 2} \leq 100 ; N_{M H P} \leq 50 ; N_{B} \leq 2,000 ; N_{F C} \leq 7,000 ; N_{W t E} \leq 2,000 ; N_{R R} \leq 1,000$ $N_{E} \leq 25,000 ; N_{H T} \leq 25,000 ; N_{S} \leq 80 ; N_{S C} \leq 100,000 ; N_{T} \leq 6,000 ; N_{I} \leq 9,000$.

The above-mentioned maximum values could represent practical limitations on the installation of the systems, such as land-use restrictions and available catchment areas for the MHP plants.

To relax the imposed constraints in the simulation of the proposed method, a penalty term is added to the total costs of the conceptualised micro-grids (expressed as objective functions in Eqs. (26), (27), (30)). The penalty term adds a semi-infinite penalty value - enabled using a binary variable - in case of violation of any of the aforementioned constraints, which are dictated by the practical feasibility and end-user comfort requirements or derived from the considered precise life-cycle assessment approach.

\subsection{Overview of the proposed modelling framework}

The overview of the proposed generic modelling framework to optimally design on- and off-grid MGs is shown in Fig. 6. This modelling framework is employed in this study to optimally design the devised hydrogen-based test-case MGs (through minimizing the above-mentioned objective functions, whilst also relaxing the expressed constraints), whereby the performances of the considered meta-heuristics are assessed.

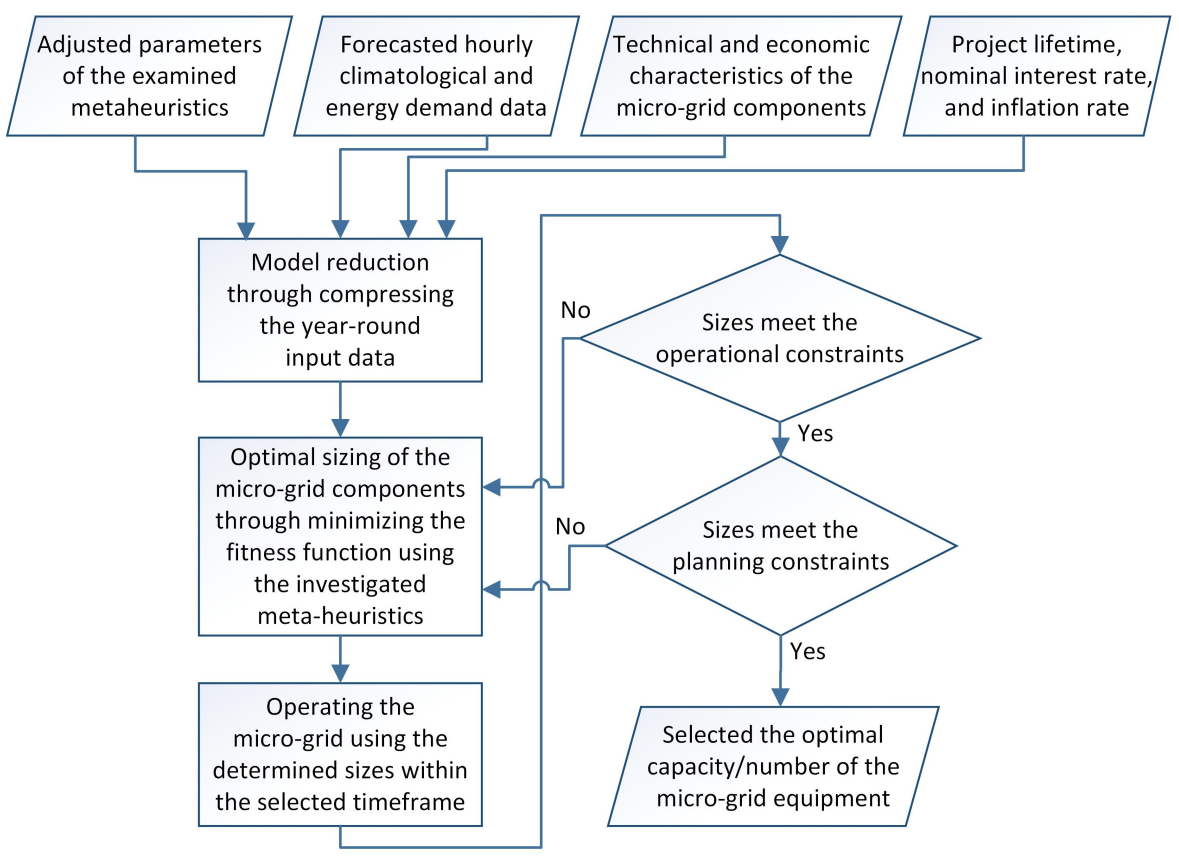

Fig. 6. Flowchart of the proposed meta-heuristic optimization-based framework for the optimal design of MGs. 


\section{Case study sites and input data}

In order to evaluate the financial viability of the suggested hydrogen-based MG designs in real-world applications, as well as to investigate the efficiency of the considered meta-heuristics, three case studies were analysed utilising the developed methodology in Section 3. The proposed notional MG 1, MG 2, and MG 3 networks were respectively considered to provide electricity and transportation fuel to the following three communities in New Zealand over a 20-year period: (1) the remote community residing on Stewart Island (latitude $46.9973^{\circ} \mathrm{S}$, longitude $167.8372^{\circ} \mathrm{E}$ ) with a population of around 400 people; (2) a semi-urban community residing in the Ohakune town (latitude $39.4180^{\circ} \mathrm{S}$, longitude $175.3985^{\circ} \mathrm{E}$ ) with a permanent population of around 1,000 that rises to around 8,500 people during the winter ski season; and (3) a rural community residing in the Feilding area (latitude $40.2253^{\circ} \mathrm{S}$, longitude $175.5675^{\circ} \mathrm{E}$ ) with a population of around 350 people. The locations of these case study sites are shown in Fig. 7 on the New Zealand's National Grid map [97]. In the figure, the filled blue and silvery circles respectively indicate the main load and generation centres; while the grey, mustard yellow, and blue lines respectively indicate the 350,220 , and $110 \mathrm{kV}$ transmission lines.

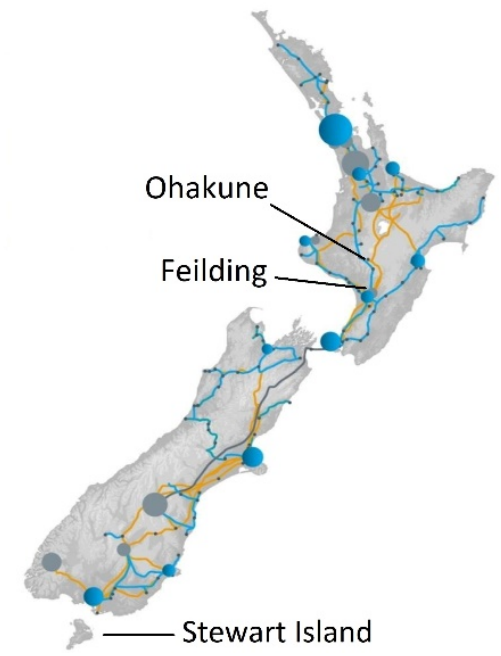

Fig. 7. Locations of the considered case study sites on the New Zealand's National Grid map [97].

The following points should also be noted:

1. All the costs are expressed in U.S. dollars, except as otherwise noted. Where required, they are converted to U.S. dollars by the mean 2018 currency exchange rates.

2. The cost associated with the DC dump load is assumed to be negligible.

3. The costs and efficiencies of the power converters shown inside the dashed lines in Figs. 1, 3, and 5, as well as the illustrated compressors, are incorporated in their respective components.

4. The cost and efficiency of the MPPT apparatus are taken into consideration in the cost and efficiency of the PV generator.

5. For all three case study sites, there are existing overhead power distribution lines and we are not expecting a large hydrogen distribution network.

6. This study builds on prior feasibility study performed on the potentials for the utilisation of RESs in the considered locations [98], [99].

\subsection{Techno-economic specifications}

The technical and financial parameters of the components of the proposed hydrogen-based MGs are presented in Table 2 [34], [62], [64], [66], [68], [70], [71], [74], [78], [80], [82], [84], [100]-[106]. 
Table 2. Techno-economic specifications of the components utilised within the structures of the three MGs.

\begin{tabular}{|c|c|c|c|c|c|c|}
\hline Component & Product model & Capital cost $\mathrm{t}^{\mathrm{a}}$ & Replacement cost ${ }^{\mathrm{a}}$ & $O \& M \cos t^{a}$ & $\begin{array}{c}\text { Lifetime } \\
\text { (year) }\end{array}$ & Reference(s) \\
\hline PV panel & CS6U-325P & \$700/unit & $\$ 500 /$ unit & \$14/unit/yr & 20 & {$[34]$} \\
\hline \multirow{2}{*}{ Wind turbine } & Fuhrländer FL30 & $\$ 83,000 /$ unit & $\$ 75,000 /$ unit & $\$ 3,100 /$ unit/yr & 20 & \multirow{2}{*}{ [62], [102] } \\
\hline & Fuhrländer FL100 & $\$ 220,000 /$ unit & $\$ 200,000 /$ unit & $\$ 8,600 /$ unit/yr & 20 & \\
\hline Micro-hydro power plant & Natel FreeJet FJ-7A & $\$ 55,000 /$ unit & $\$ 50,000 /$ unit & $\$ 1,900 /$ unit/yr & 25 & {$[80]$} \\
\hline Waste-to-energy plant & Generic & $\$ 9,600 / \mathrm{kW}$ & $\$ 7,300 / \mathrm{kW}$ & $\$ 490 / \mathrm{kW} / \mathrm{yr}$ & 10 & {$[64]$} \\
\hline Biopower plant & Generic & $\$ 9,150 / \mathrm{kW}$ & $\$ 7,500 / \mathrm{kW}$ & $\$ 430 / \mathrm{kW} / \mathrm{yr}$ & 20 & {$[71],[82]$} \\
\hline Super-capacitor & MAXWELL EDLC & \$32/unit & \$32/unit & $\$ 0.64 /$ unit/yr & 10 & {$[66],[103]$} \\
\hline Electrolyser & Generic & $\$ 1,000 / \mathrm{kW}$ & $\$ 1,000 / \mathrm{kW}$ & $\$ 20 / \mathrm{kW} / \mathrm{yr}$ & 15 & {$[68]$} \\
\hline Reactor-reformer & Generic & $\$ 14,500 / \mathrm{kg} \mathrm{H}_{2} / \mathrm{h}$ & $\$ 13,200 / \mathrm{kg} \mathrm{H}_{2} / \mathrm{h}$ & $\$ 910 / \mathrm{kg} \mathrm{H}_{2} / \mathrm{h} / \mathrm{yr}$ & 20 & {$[105]$} \\
\hline $\mathrm{H}_{2}$ reservoir & Generic & $\$ 470 / \mathrm{kg} \mathrm{H}_{2}$ & $\$ 470 / \mathrm{kg} \mathrm{H}_{2}$ & $\$ 9.4 / \mathrm{kg} \mathrm{H}_{2} / \mathrm{yr}$ & 20 & {$[70]$} \\
\hline Fuel cell & Generic & $\$ 2,400 / \mathrm{kW}$ & $\$ 2,400 / \mathrm{kW}$ & $\$ 48 / \mathrm{kW} / \mathrm{yr}$ & 5 & {$[106]$} \\
\hline Inverter & Generic & $\$ 750 / \mathrm{kW}$ & $\$ 750 / \mathrm{kW}$ & $\$ 15 / \mathrm{kW} / \mathrm{yr}$ & 15 & {$[100],[101]$} \\
\hline Transformer & Generic & $\$ 100 / \mathrm{kVA}$ & $\$ 900 / \mathrm{kVA}$ & $\$ 5 / \mathrm{kVA} / \mathrm{yr}$ & 20 & {$[84],[85]$} \\
\hline $\mathrm{H}_{2}$ refilling station & Pure Energy Centre & $\$ 10,000 / \mathrm{kg} \mathrm{H}_{2} / \mathrm{h}$ & $\$ 5,000 / \mathrm{kg} \mathrm{H}_{2} / \mathrm{h}$ & $\$ 350 / \mathrm{kg} \mathrm{H}_{2} / \mathrm{h} / \mathrm{yr}$ & 20 & {$[74],[78],[104]$} \\
\hline
\end{tabular}

${ }^{a}$ All costs were normalized to 2018 U.S. dollars.

\subsection{Climatological data}

All the climatological data were sourced from the New Zealand's National Institute of Water and Atmospheric Research (NIWA) CLiFlo database [107]. In this regard, the 10 years (2009-2018) climatological data collected for the considered locations were averaged at intervals of 1-hour or 1-month, depending on the availability of data. Finally, for the sake of computational burden alleviation, the data compression-based model reduction technique presented in sub-section 3.1 is applied to the hourly-basis, year-round historical input data streams.

The heat map-like plots in Fig. 8 show the monthly averaged daily wind speed profiles at the considered three case study sites. Since the wind speed data were recorded at the height of $48 \mathrm{~m}$ at each site, where necessary, they were normalized to the heights of 27 and $38 \mathrm{~m}$, in accordance with the hub heights of the FL30 and FL100 WT generators using Eq. (1). The contour plots in Fig. 9 show the monthly averaged daily solar irradiance at case study sites 2 and 3. The monthly mean minimum and maximum daily temperatures at case study sites 2 and 3 are shown in Fig. 10. The monthly mean streamflow profiles for the Mangawhero River and the Rangitikei River, which are respectively situated at case study sites 2 and 3 are shown in Fig. 11. The monthly mean estimated available biomass profiles at the three sites, incorporating both the agricultural biomass and the organic fraction of the MSW (where applicable), are shown in Fig. 12. The Ohakune town sources a high proportion of New Zealand's carrots (thereby, creating high amounts of agricultural residues), resulting in higher amounts of the total available biomass at this site as compared to the other two sites. Furthermore, the organic and non-organic fractions of the MSW are estimated, assuming that each individual in the population produces $600 \mathrm{~g}$ of wet waste and $2 \mathrm{~kg}$ of dry waste per day [71]. The aggregated biowaste is fed to the reactor-reformer system/biopower plant (according to the system structure) on a constant basis throughout the day, creating a uniform hydrogen/electricity production output profile. 


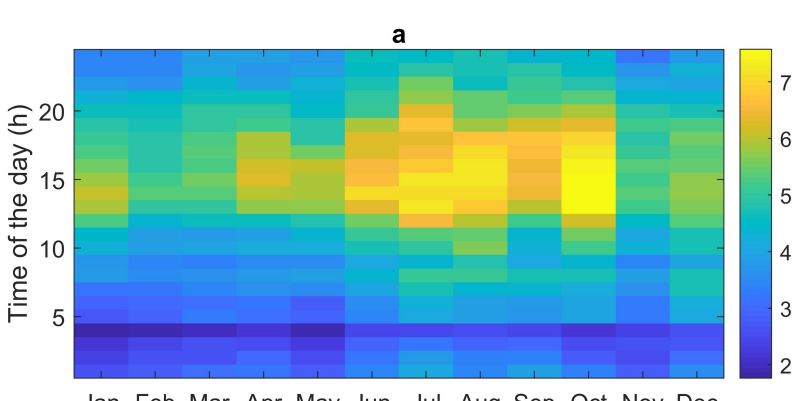

Jan Feb Mar Apr May Jun Jul Aug Sep Oct Nov Dec Months

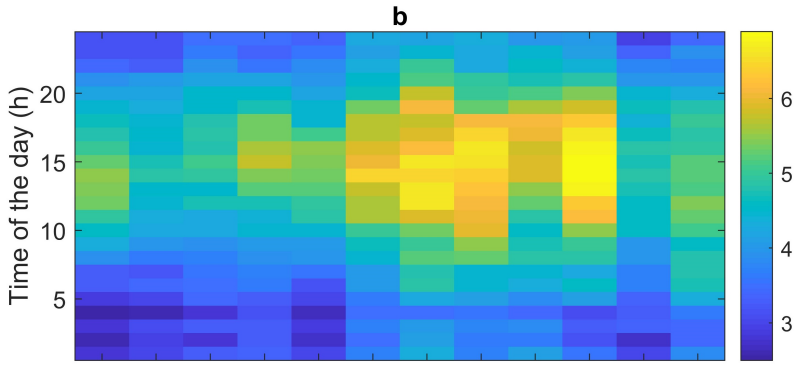

Jan Feb Mar Apr May Jun Jul Aug Sep Oct Nov Dec Months

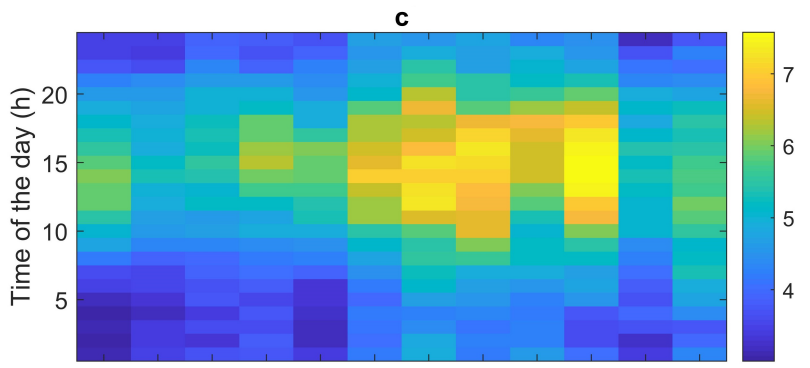

Jan Feb Mar Apr May Jun Jul Aug Sep Oct Nov Dec Months

Fig. 8. Monthly averaged daily wind speed profile (m/s) at: (a) Stewart Island; (b) the Ohakune town; and (c) the Feilding area.
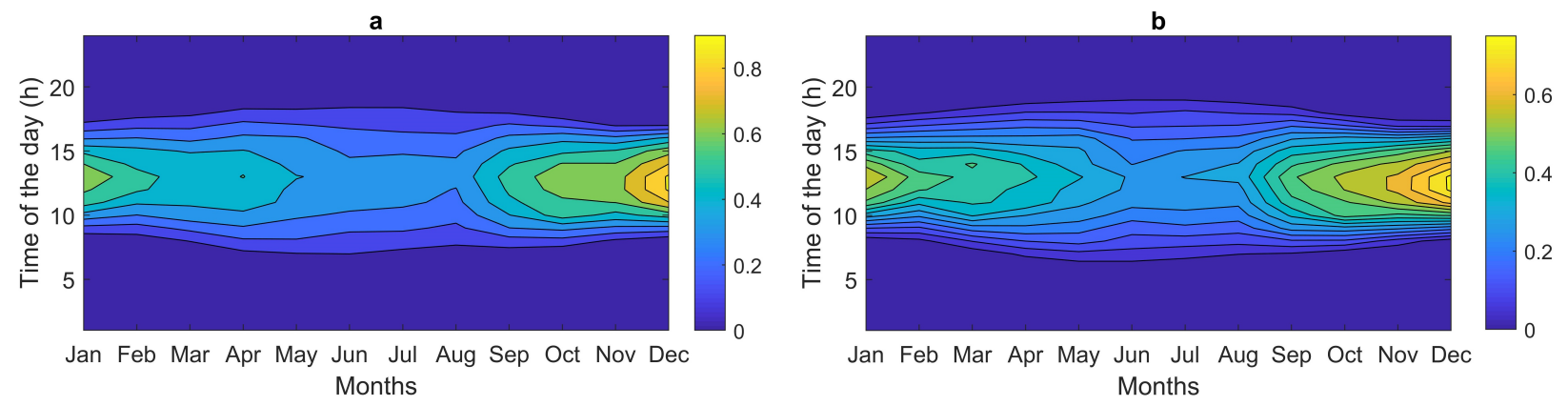

Fig. 9. Monthly averaged daily solar irradiance profile $\left(\mathrm{kW} / \mathrm{m}^{2}\right)$ at the: (a) Ohakune town; and (b) Feilding area.
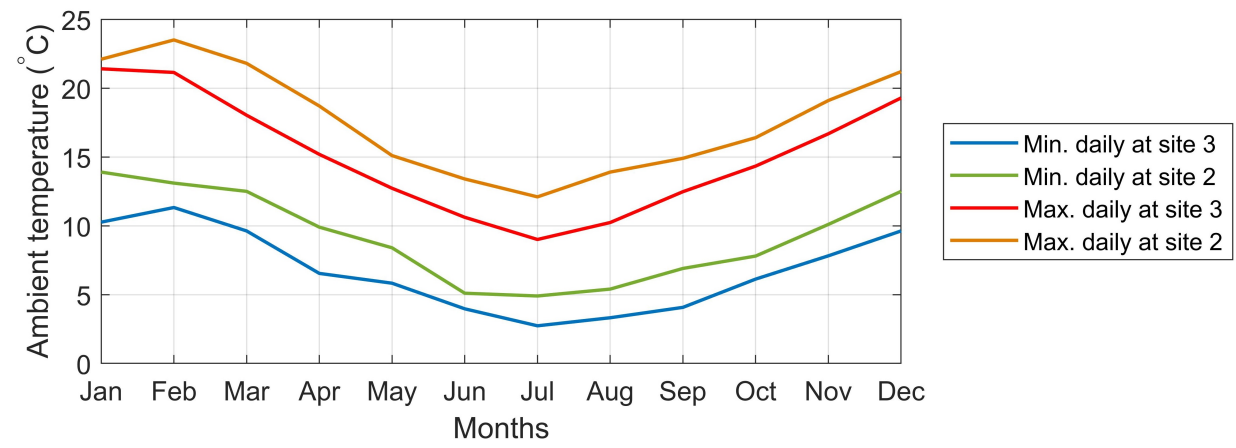

Fig. 10. Monthly averaged minimum and maximum daily air temperature profiles $\left({ }^{\circ} \mathrm{C}\right)$ at the Ohakune town and the Feilding area. 

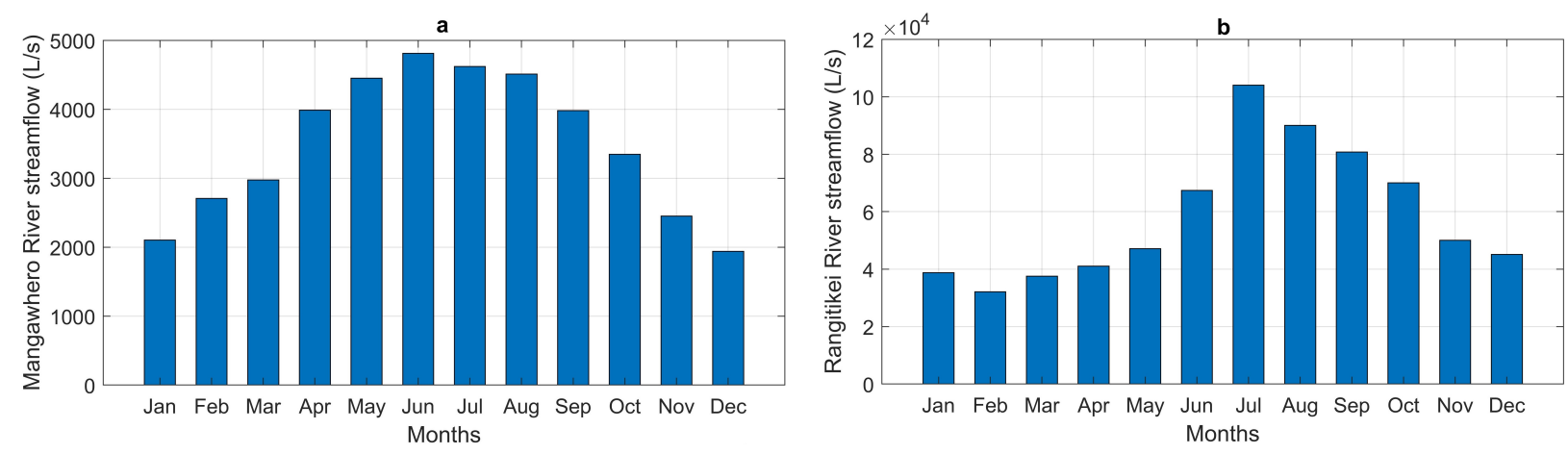

Fig. 11. Monthly mean streamflow profile (L/s) for the: (a) Mangawhero River; and (b) Rangitikei River.

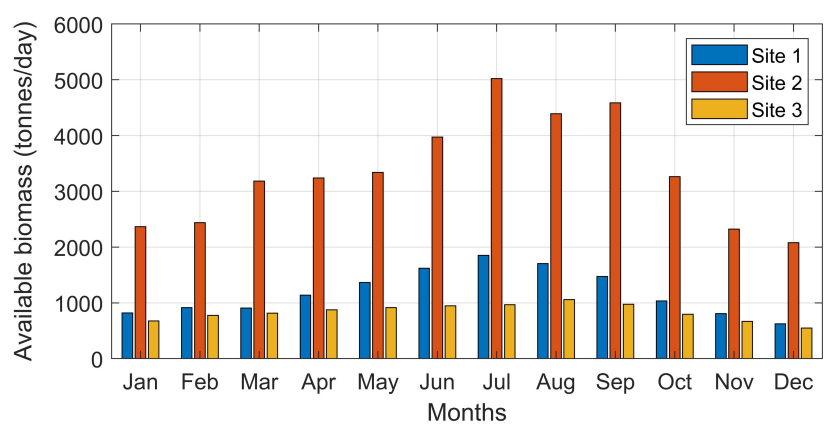

Fig. 12. Monthly mean estimated available biomass profiles for the three considered case study sites.

\subsection{Energy demand data}

The forecasted monthly averaged daily profiles for the hourly residential electrical loads, imposed on the considered MG networks over a year, are shown in 3D plots in Fig. 13. The load power profiles for Stewart Island and the Feilding area sites were estimated in accordance to the New Zealand GREEN grid household electricity demand study [108], while this was conducted with respect to the actual data collected for the Ohakune's current electricity network in the second case study [99]. The predicted residential load power profile for the Ohakune town covers the effect of seasonal variation in load demand owing to the presence of skiers in the wintertime, resulting in substantial growth in the demand for electricity during this time period. Also, the typical daily hydrogen load profiles imposed on the considered MG systems, with the aim of decarbonising the transport sector, are shown in Fig. 14. In obtaining these hydrogen load patterns, the following assumptions were made:

1. Five Hydrogenesis Passenger Ferry fuel cell-powered marine vessels have to be integrated into system 1 . These ferries are used to transport passengers between Stewart Island and the Bluff, Southland, New Zealand.

2. A fleet of 300 light-duty fuel cell-powered vehicles, all of which are of the brand model Riversimple Rasa, utilise the hydrogen station integrated into system 2.

3. Five NH2 fuel cell-powered tractors, as well as five Hyundai fuel cell-powered trucks, are integrated into system 3.

4. In the MG test-cases 1 and 3, the vessels/vehicles are refuelled in the early morning hours (between 1 and 6 $\mathrm{am}$ ), i.e. the light residential load hours, to fill up the valley in the total daily energy demand profiles of the corresponding MG systems. In this respect, we allowed the challenges associated with the integration of green vehicles/vessels into these MGs to be opportunities for flattening the overall profiles for energy demand, whereby the levelized costs of energy of these MGs are reduced.

5. In the second MG test-case system, it is assumed that the vehicles arrive at the station following a Normal distribution, between the hours of 9 am and $20 \mathrm{pm}$. Accordingly, the vehicles are refuelled on a first come first serve $M / M / c$ queuing model [109]. 
6. The hydrogen tanks of the ferries, light-duty vehicles, and heavy-duty vehicles need to be refilled every 4, 3, and 5 days respectively. Taking into account this assumption, the hydrogen demands of the ferries and heavyduty vehicles are distributed throughout the working days to flatten the peaks in their load patterns.

a

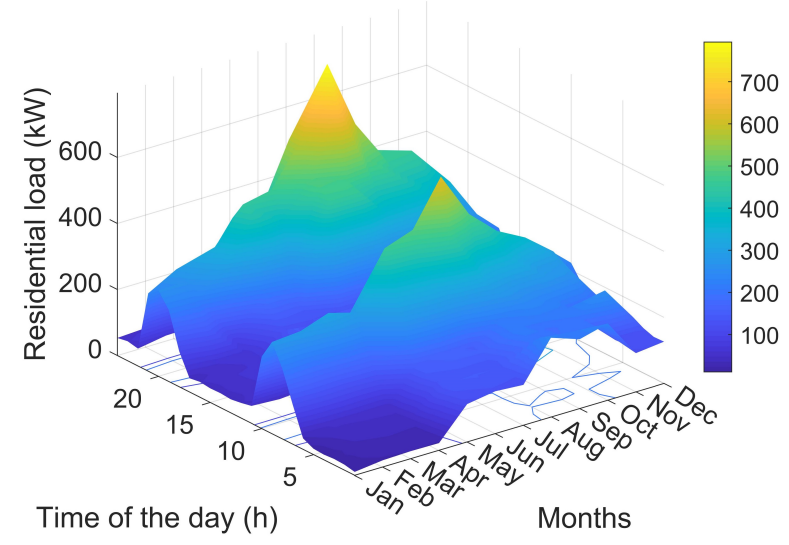

b

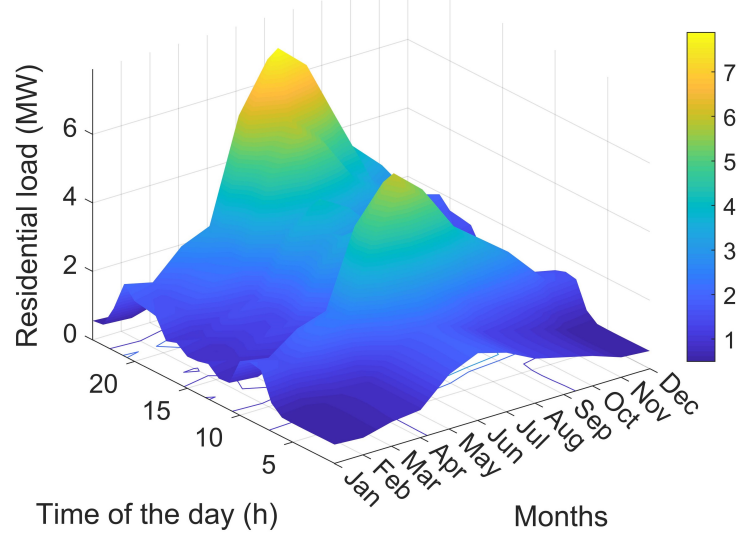

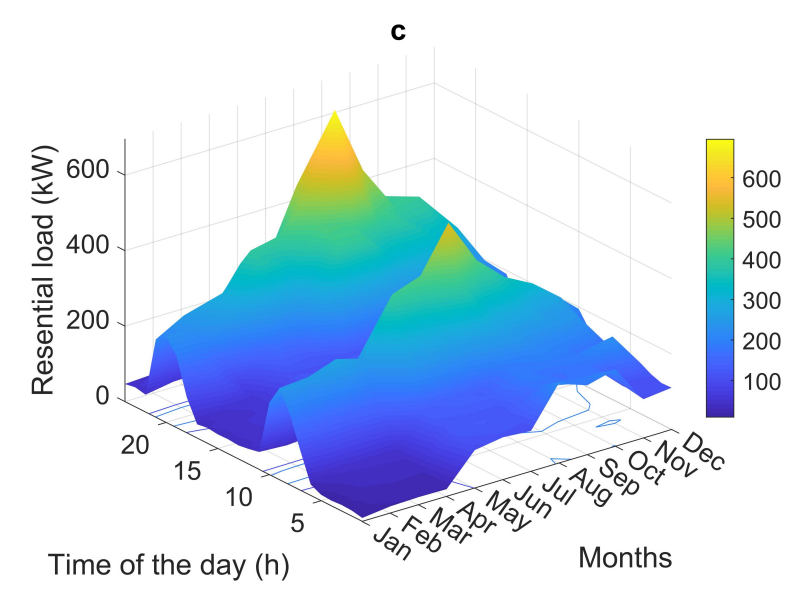

Fig. 13. Forecasted monthly mean daily residential electrical load power profiles on the proposed MG networks for: (a) Stewart Island; (b) the Ohakune town; and, (c) the Feilding area.

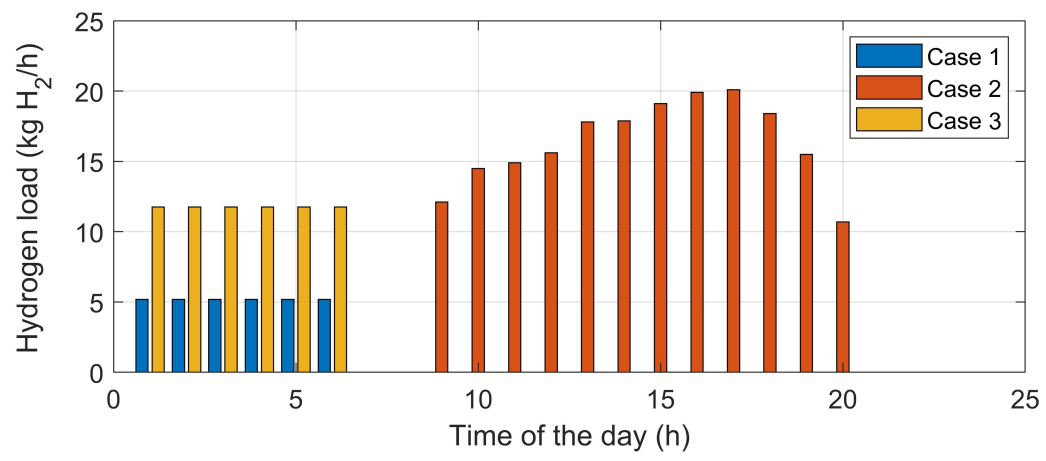

Fig. 14. Typical daily hydrogen load profiles on the MGs following the devised implementation strategies to adopt hydrogen vehicles/vessels. 


\section{Simulation results and discussion}

The numerical simulations were conducted on the Intel ${ }^{\circledR}$ Core $^{\mathrm{TM}}$ i7-8700, $3.20 \mathrm{GHz}$ CPU with a RAM of $16 \mathrm{~GB}$. All models were coded in the MATLAB 9.5 software [110].

\subsection{Performance comparison of the selected optimizers}

In order to rank the performance of the selected algorithms, a statistics-driven framework is adopted in this study, which compares the algorithms' efficiencies, taking into account their effectiveness in solving the three MG planning problems considered. The proposed comparison framework employs the following four metrics: the best-case results (Best), the worst-case results (Worst), the mean results (Mean), and the median results (Median) of the TNPCs, achieved over 30 independent trials for every MG sample. The Best, Worst, and Mean indicators reflect the accuracy of the algorithm, while the Median indicator reveals its precision (i.e. the number of hits to the optimum solution out of 30 simulation runs). Also, in order to ensure a fair comparison, the maximum number of iterations, as well as the number of their search agents, are kept constant for all the investigated algorithms, and equal to 300 and 45 , respectively.

The comparison framework does not include any indicators to evaluate the convergence speeds of the algorithms. The reason lies in the fact that the MG systems are usually planned for a projected 20- to 30-year period, making the computational cost an insubstantial metric for the comparative evaluation of different optimizers, unless they are associated with intractable computational complexities, which has not been the case here. In this regard, the calculated indicators for each MG instance are first averaged (Avg. 1). The meta-heuristics are then scored locally, based on the Avg. 1 criterion, obtained for every MG system. The mean values of the scores obtained for different optimizers under different testing conditions (when applied to different MG topologies (in terms of both grid connection layout and energy generation components) with different loading and meteorological conditions, are then calculated. These mean values (Avg.2) eventually determine the final ranks of the analysed meta-heuristic optimization algorithms. Accordingly, Table 3 ranks the performance of the analysed algorithms. The following notes are made to provide a better interpretation of the results presented in Table 3:

1. When the Mean is lower than the Median, the distribution of the results obtained over 30 trials is said to be left-skewed (which appears as a right-leaning curve), meaning that the stability of the optimizer against different initial random solutions is low. Contrariwise, in the cases that the Mean is higher than the Median, the distribution of the results is skewed to the right and the optimizer is highly robust against the variations of initial guess.

2. The scoring procedure presented in Table 3, eliminates the need to weight the Avg. 1 criteria in obtaining the Avg. 2 metrics. Indeed, it leads to considering the same weight for all the identified performances of the algorithms on different test systems.

From Table 3, the following conclusions can be drawn:

1. It is possible that dissimilar evaluations arise, if the meta-heuristics are applied to a specific problem in different runs, or when they are applied to different MG planning problems. Therefore, their efficiencies must be compared based on their performance on different test cases, whilst also taking a statistical approach, to avoid incomplete, short-sighted, and ultimately mistaken comparative evaluations.

2. By comparing the results obtained by the GA, the PSO, the HGA-PSO, the ABC, the ACO, and the HABC$\mathrm{ACO}$, it can be deduced that the hybrid version of two single algorithms usually outperforms any of them alone.

3. The MFOA, which is a recently developed meta-heuristic, outperforms all the other examined algorithms, albeit by a small margin, not only in terms of the overall performance measure, but also in terms of all the individual indicators.

4. Based on the numerical tests undertaken in this study, the relative error in approximating the global optima (by comparing the Best indices of the MFOA (which has shown the greatest performance) and the DA (which has shown the weakest performance)) could be as high as $2.4 \%, 1.6 \%$, and $6.5 \%$ respectively from the three target systems, equating to cost savings of $\$ 216,922, \$ 683,878$, and $\$ 346,180$, respectively.

5. According to the Avg. 2 criterion, the performance of the selected algorithms can be ranked (within the context of the research area) as follows: the MFOA $<$ the $\mathrm{HGA}-\mathrm{PSO}<$ the GA $<$ the $\mathrm{PSO}<$ the HABC-ACO 
$<$ the $\mathrm{ABC}<$ the $\mathrm{ACO}<$ the IHSA $<$ the $\mathrm{MVO}<$ the $\mathrm{GWO}<$ the $\mathrm{BA}<$ the $\mathrm{BB}-\mathrm{BC}<$ the $\mathrm{CSA}<$ the $\mathrm{FA}<$ the $\mathrm{ALO}<$ the $\mathrm{WEO}<$ the $\mathrm{SCA}<$ the GOA $<$ the $\mathrm{SSA}<$ the DA.

Table 3. Statistics-based performance comparison of the algorithms in minimizing the TNPCs of the MGs (\$).

\begin{tabular}{|c|c|c|c|c|c|c|c|c|c|}
\hline Alg. & Sys. & Best & Worst & Mean & Median & Avg. 1 & Score & Avg. 2 & Rank \\
\hline \multirow{3}{*}{ PSO } & MG 1 & $9,381,048$ & $9,381,982$ & $9,381,554$ & $9,381,048$ & $9,381,408$ & 4 & & \\
\hline & MG 2 & $44,031,041$ & $44,185,656$ & $44,103,854$ & $44,031,041$ & $44,087,898$ & 4 & 3.67 & 4 \\
\hline & MG 3 & $5,344,083$ & $5,355,001$ & $5,346,527$ & $5,344,083$ & $5,347,424$ & 3 & & \\
\hline \multirow{3}{*}{ GA } & MG 1 & $9,379,004$ & $9,381,746$ & $9,380,531$ & $9,379,004$ & $9,380,071$ & 3 & & \\
\hline & MG 2 & $44,025,568$ & $44,188,784$ & $44,104,547$ & $44,025,568$ & $44,086,117$ & 3 & 3.33 & 3 \\
\hline & MG 3 & $5,344,448$ & $5,359,452$ & $5,347,387$ & $5,344,448$ & $5,348,934$ & 4 & & \\
\hline \multirow{3}{*}{$\begin{array}{c}\text { HGA- } \\
\text { PSO }\end{array}$} & MG 1 & $9,372,109$ & $9,376,111$ & $9,374,557$ & $9,372,109$ & $9,373,722$ & 2 & & \\
\hline & MG 2 & $44,017,956$ & $44,190,541$ & $44,101,850$ & $44,017,956$ & $44,082,076$ & 2 & 2 & 2 \\
\hline & MG 3 & $5,343,540$ & $5,354,659$ & $5,347,245$ & $5,343,540$ & $5,347,246$ & 2 & & \\
\hline \multirow{3}{*}{$\mathrm{ABC}$} & MG 1 & $9,383,870$ & $9,401,540$ & $9,389,321$ & $9,383,870$ & $9,389,650$ & 6 & & \\
\hline & MG 2 & $44,036,141$ & $44,197,553$ & $44,105,521$ & $44,036,141$ & $44,093,839$ & 6 & 6.33 & 6 \\
\hline & MG 3 & $5,350,114$ & $5,386,327$ & $5,361,542$ & $5,350,114$ & $5,362,002$ & 7 & & \\
\hline \multirow{3}{*}{$\mathrm{ACO}$} & MG 1 & $9,382,219$ & $9,403,274$ & $9,391,374$ & $9,382,219$ & $9,389,772$ & 7 & & \\
\hline & MG 2 & $44,039,995$ & $44,195,256$ & $44,102,356$ & $44,039,995$ & $44,094,400$ & 7 & 6.67 & 7 \\
\hline & MG 3 & $5,353,607$ & $5,371,258$ & $5,360,618$ & $5,353,607$ & $5,359,773$ & 6 & & \\
\hline \multirow{3}{*}{$\begin{array}{c}\text { HABC- } \\
\text { ACO }\end{array}$} & MG 1 & $9,383,955$ & $9,384,741$ & $9,384,005$ & $9,383,955$ & $9,384,166$ & 5 & & \\
\hline & MG 2 & $44,032,985$ & $44,191,007$ & $44,104,741$ & $44,032,985$ & $44,090,430$ & 5 & 5 & 5 \\
\hline & MG 3 & $5,348,927$ & $5,355,668$ & $5,350,493$ & $5,348,927$ & $5,351,004$ & 5 & & \\
\hline \multirow{3}{*}{ ALO } & MG 1 & $9,386,072$ & $9,415,984$ & $9,396,482$ & $9,389,974$ & $9,397,128$ & 13 & & \\
\hline & MG 2 & $44,045,750$ & $44,215,187$ & $44,129,001$ & $44,091,030$ & $44,120,242$ & 13 & 15 & 15 \\
\hline & MG 3 & $5,675,981$ & $5,913,542$ & $5,792,110$ & $5,794,115$ & $5,793,937$ & 19 & & \\
\hline \multirow{3}{*}{ IHSA } & MG 1 & $9,386,106$ & $9,406,002$ & $9,391,571$ & $9,390,143$ & $9,393.456$ & 10 & & \\
\hline & MG 2 & $44,041,129$ & $44,199,522$ & $44,101,077$ & $44,041,129$ & $44,095,714$ & 8 & 8.67 & 8 \\
\hline & MG 3 & $5,350,974$ & $5,379,651$ & $5,363,444$ & $5,360,457$ & $5,363,632$ & 8 & & \\
\hline \multirow{3}{*}{ BB-BC } & MG 1 & $9,391,570$ & $9,416,098$ & $9,397,021$ & $9,391,987$ & $9,399,169$ & 15 & & \\
\hline & MG 2 & $44,046,021$ & $44,215,199$ & $44,130,546$ & $44,092,365$ & $44,121,033$ & 14 & 12.67 & 12 \\
\hline & MG 3 & $5,354,027$ & $5,391,610$ & $5,364,771$ & $5,354,027$ & $5,366,109$ & 9 & & \\
\hline \multirow{3}{*}{ MFOA } & MG 1 & $9,142,109$ & $9,144,576$ & $9,143,850$ & $9,142,109$ & $9,143,159$ & 1 & & \\
\hline & MG 2 & $43,881,018$ & $43,890,577$ & $43,884,338$ & $43,881,018$ & $43,884,238$ & 1 & 1 & 1 \\
\hline & MG 3 & $\mathbf{5 , 3 3 0 , 0 3 7}$ & $5,339,874$ & $5,333,547$ & $5,330,037$ & $5,333,374$ & 1 & & \\
\hline \multirow{3}{*}{ SCA } & MG 1 & $9,392,449$ & $9,418,995$ & $9,401,825$ & $9,393,736$ & $9,401,751$ & 17 & & \\
\hline & MG 2 & $44,052,960$ & $44,221,652$ & $44,139,634$ & $44,110,111$ & $44,131,089$ & 18 & 15.66 & 17 \\
\hline & MG 3 & $5,361,540$ & $5,402,329$ & $5,383,669$ & $5,389,495$ & $5,384,258$ & 12 & & \\
\hline \multirow{3}{*}{ MVO } & MG 1 & $9,383,775$ & $9,406,108$ & $9,388,937$ & $9,383,775$ & $9,390,649$ & 9 & & \\
\hline & MG 2 & $44,040,985$ & $44,202,101$ & $44,111,520$ & $44,040,985$ & $44,098,898$ & 9 & 9.33 & 9 \\
\hline & MG 3 & $5,360,297$ & $5,400,103$ & $5,373,639$ & $5,388,436$ & $5,380,619$ & 10 & & \\
\hline \multirow{3}{*}{ WEO } & MG 1 & $9,386,254$ & $9,416,024$ & $9,396,552$ & $9,391,309$ & $9,397,534$ & 14 & & \\
\hline & MG 2 & $44,053,133$ & $44,222,000$ & $44,144,984$ & $44,115,133$ & $44,133,813$ & 19 & 15.33 & 16 \\
\hline & MG 3 & $5,361,990$ & $5,402,773$ & $5,383,990$ & $5,390,061$ & $5,384,704$ & 13 & & \\
\hline \multirow{3}{*}{ GWO } & MG 1 & $9,384,002$ & $9,404,870$ & $9,386,654$ & $9,385,192$ & $9,390,180$ & 8 & & \\
\hline & MG 2 & $44,041,192$ & $44,203,041$ & $44,122,652$ & $44,079,572$ & $44,111,615$ & 10 & 10.66 & 10 \\
\hline & MG 3 & $5,362,555$ & $5,409,351$ & $5,386,473$ & $5,392,652$ & $5,387,758$ & 14 & & \\
\hline \multirow{3}{*}{ CSA } & MG 1 & $9,392,004$ & $9,419,259$ & $9,397,508$ & $9,392,966$ & $9,400,434$ & 16 & & \\
\hline & MG 2 & $44,045,698$ & $44,205,009$ & $44,128,635$ & $44,089,190$ & $44,117,133$ & 12 & 13 & 13 \\
\hline & MG 3 & $5,361,478$ & $5,401,691$ & $5,389,006$ & $5,379,309$ & $5,382,871$ & 11 & & \\
\hline & MG 1 & $9,393,406$ & $9,419,889$ & $9,403,574$ & $9,396,555$ & $9,403,356$ & 19 & & \\
\hline SSA & MG 2 & $44,051,553$ & $44,219,632$ & $44,137,254$ & $44,100,856$ & $44,127,324$ & 17 & 18 & 19 \\
\hline & MG 3 & $5,675,505$ & $5,912,888$ & $5,693,343$ & $5,790,128$ & $5,767,966$ & 18 & & \\
\hline & MG 1 & $9,392,907$ & $9,419,962$ & $9,401,939$ & $9,395,680$ & $9,402,622$ & 18 & & \\
\hline GOA & MG 2 & $44,049,155$ & $44,217,112$ & $44,133,980$ & $44,095,333$ & $44,123,895$ & 16 & 17 & 18 \\
\hline & MG 3 & $5,674,547$ & $5,911,748$ & $5,689,900$ & $5,758,609$ & $5,758,701$ & 17 & & \\
\hline & MG 1 & $9,395,031$ & $9,501,430$ & $9,452,684$ & $9,472,200$ & $9,455,336$ & 20 & & \\
\hline DA & MG 2 & $44,564,896$ & $44,984,021$ & $44,785,652$ & $44,874,654$ & $44,779,806$ & 20 & 20 & 20 \\
\hline & MG 3 & $5,676,217$ & $6,010,872$ & $6,000,909$ & $6,006,537$ & $5,923,634$ & 20 & & \\
\hline & MG 1 & $9,385,662$ & $9,419,205$ & $9,393,101$ & $9,385,662$ & $9,395,908$ & 11 & & \\
\hline BA & MG 2 & $44,041,543$ & $44,204,195$ & $44,123,563$ & $44,085,856$ & $44,113,789$ & 11 & 12.33 & 11 \\
\hline & MG 3 & $5,362,751$ & $5,409,399$ & $5,386,982$ & $5,399,505$ & $5,389,659$ & 15 & & \\
\hline
\end{tabular}




\begin{tabular}{cccccccccc}
\cline { 8 - 11 } \multirow{2}{*}{ FA } & MG 1 & $9,384,584$ & $9,421,009$ & $9,394,741$ & $9,384,584$ & $9,396,230$ & 12 & \\
& MG 2 & $44,046,999$ & $44,215,985$ & $44,133,630$ & $44,093,363$ & $44,122,494$ & 15 & 14.33 & 14 \\
& MG 3 & $5,364,802$ & $5,411,350$ & $5,399,008$ & $5,391,540$ & $5,391,675$ & 16 & & \\
\hline
\end{tabular}

In order to establish a better understanding of how the TNPCs are distributed among the MGs' components, or, put differently, to reveal the sizes determined by the considered algorithms, the optimum capacity planning results obtained for the MG 1, MG 2, and MG 3 instances are reported in Table 4. These results are based on the best-case results obtained by the MFOA after 30 independent simulation runs (bolded in Table 3). From now on, all the analyses will be made with respect to the results gained in these optimization runs. Moreover, for the components, whose optimum capacities (and not quantities) are under question (i.e. continuous variables), the optimum sizes are rounded up to the nearest integer, except for the reactor-reformer and hydrogen station, whose capacities are rounded up to the second decimal place.

Table 4. Breakdown of the best TNPCs obtained by the MFOA out of 30 runs for the studied MG test-case systems.

\begin{tabular}{|c|c|c|c|c|c|c|c|c|c|c|c|c|c|c|}
\hline Sys. & $\begin{array}{c}\text { PV } \\
\text { panels } \\
\text { (no.) }\end{array}$ & $\begin{array}{l}\text { FL30 } \\
\text { WTs } \\
\text { (no.) }\end{array}$ & $\begin{array}{l}\text { FL100 } \\
\text { WTs } \\
\text { (no.) }\end{array}$ & $\begin{array}{c}\text { Bio- } \\
\text { power } \\
(\mathrm{kW})\end{array}$ & $\begin{array}{l}\text { SCs } \\
\text { (no.) }\end{array}$ & $\begin{array}{l}\text { MHPs } \\
\text { (no.) }\end{array}$ & $\begin{array}{l}\text { Elec. } \\
(\mathrm{kW})\end{array}$ & $\begin{array}{c}\mathrm{H}_{2} \operatorname{tank} \\
(\mathrm{kg})\end{array}$ & $\begin{array}{c}\text { Fuel } \\
\text { cell } \\
(\mathrm{kW})\end{array}$ & $\begin{array}{l}\text { Inv. } \\
(\mathrm{kW})\end{array}$ & $\begin{array}{l}\text { Reac.-Ref. } \\
\left(\mathrm{kg} \mathrm{H}_{2} / \mathrm{h}\right)\end{array}$ & $\begin{array}{c}\mathrm{WtE} \\
(\mathrm{kW})\end{array}$ & $\begin{array}{l}\text { Trans. } \\
\text { (kVA) }\end{array}$ & $\begin{array}{c}\mathrm{H}_{2} \text { station } \\
\left(\mathrm{kg} \mathrm{H}_{2} / \mathrm{h}\right)\end{array}$ \\
\hline MG 1 & N/A & 36 & N/A & $\mathrm{N} / \mathrm{A}$ & 9,714 & $\mathrm{~N} / \mathrm{A}$ & 1,402 & 901 & 486 & 794 & 2.49 & 13 & N/A & 3.20 \\
\hline MG 2 & 2,991 & N/A & 41 & 73 & 51,417 & 17 & 9,028 & 14,401 & 3,951 & 6,703 & N/A & N/A & 4,116 & 8.14 \\
\hline MG 3 & 554 & 2 & 3 & N/A & 8,311 & 9 & 1,251 & 730 & 371 & 662 & 1.56 & 9 & 391 & 6.79 \\
\hline
\end{tabular}

\subsection{Economic and energetic analyses of the developed systems}

\subsubsection{Financial sustainability verifications}

The optimized TNPCs of implementing the proposed MGs at the considered case study sites, subject to meeting the reliability targets for electricity and hydrogen supply during their life-spans, are estimated to be $\$ 9,142,109$, $\$ 43,881,018$, and $\$ 5,330,037$ respectively for MG 1, MG 2, and MG 3. The bar chart in Fig. 15 shows the percentage contribution of different components to the TNPCs of the MG systems. In the figure, the revenues from selling electricity to the upstream networks (in the cases of second and third MGs) are first subtracted from the corresponding TNPCs. As can be seen in Fig. 15, the costs associated with the hydrogen storage sub-systems are the largest cost components in all the cases, which are followed by the costs associated with the wind power generation systems. By comparing the proportion of the tank to the electrolyser and fuel cell, a higher value for the capacity of the hydrogen reservoir in MG 2 is identified. This is because of the specific seasonal loading conditions on system 2. Accordingly, it can be deduced that the optimization protocol has determined the seasonal energy storage a better option than (1) buying electricity from the upstream grid to meet the seasonal peaks in electricity demand, and (2) oversizing of the components for the light-load time periods and selling the excess power to the grid.

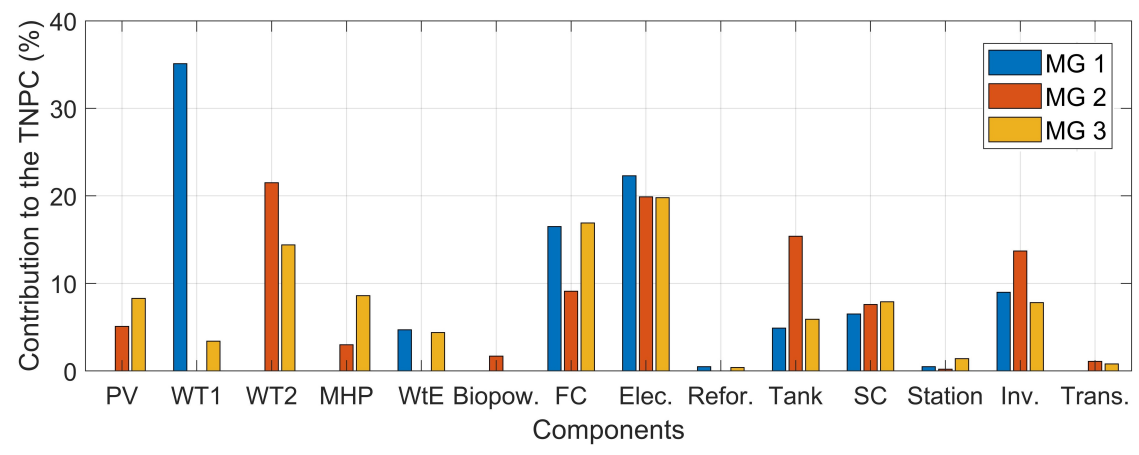

Fig. 15. Breakdown of the TNPCs associated with the MG samples.

The levelized costs of electricity and hydrogen for the studied MGs are presented in Table 5. As shown in the table, the exchange of energy with the upstream grid, along with the utilisation of solar and hydro resources, have 
significantly contributed to the energy affordability in the second and third systems. As indicated earlier, the best available resources at each location are determined by prior feasibility assessments.

At present, the average electricity price at the areas connected to the main grid is around $\$ 0.21 / \mathrm{kWh}$, in New Zealand currency, while this value rises to $\$ 0.26 / \mathrm{kWh}$ for Stewart Island, whose current power supply scheme is totally based on diesel generators operating in a centralized manner. In addition, the most up-to-date announced price for hydrogen in New Zealand is about $\$ 14 / \mathrm{kg} \mathrm{H}_{2}$, in New Zealand currency, when produced locally on small-scale, and $\$ 8.91 / \mathrm{kg}$ $\mathrm{H}_{2}$ for large-scale hydrogen production schemes [111], [112].

Table 5. Levelized costs of electricity and hydrogen of the conceptualised MG systems.

\begin{tabular}{ccc}
\hline Test-case system & $\operatorname{LCOE~}(\$ / \mathrm{kWh})^{\mathrm{a}}$ & $\mathrm{LCOH}\left(\$ / \mathrm{kg} \mathrm{H}_{2}\right)^{\mathrm{a}}$ \\
\hline MG 1 & 0.18 & 7.82 \\
MG 2 & 0.14 & 6.45 \\
MG 3 & 0.12 & 6.17 \\
\hline
\end{tabular}

${ }^{\mathrm{a}}$ The costs are reported in New Zealand currency.

It can be observed from Table 5 that the values of LCOE and LCOH for all the devised energy systems are well below the existing prices of electricity and hydrogen for grid-tied and grid-independent areas of New Zealand. These findings not only verify the effectiveness of the proposed MG design and capacity planning methodology, but also corroborate the cost-effectiveness of realizing the studied MG projects.

\subsubsection{Energy flow analyses}

In this sub-section, we report on the energy flow analyses of the conceptualised MGs using the best-estimated sizes for their components. The analyses are conducted on the reduced operational timeframe (12-months $\times 24-\mathrm{h}$ model), adopted in the optimization protocol, according to the employed data compression-based model reduction technique.

The results of the overall energy flow analyses on the generation and consumption sides are illustrated in Fig. 16 in terms of their percentage contribution to the generation or consumption of energy. In the figure, the positive values indicate the generation of energy, while the negative values represent energy consumption. Also, the total system losses include the energy losses associated with the non-ideality of the system components that are characterised by their efficiencies. The results presented in Fig. 16 can be envisioned as an energy balance outlook for the conceptualised MG networks.

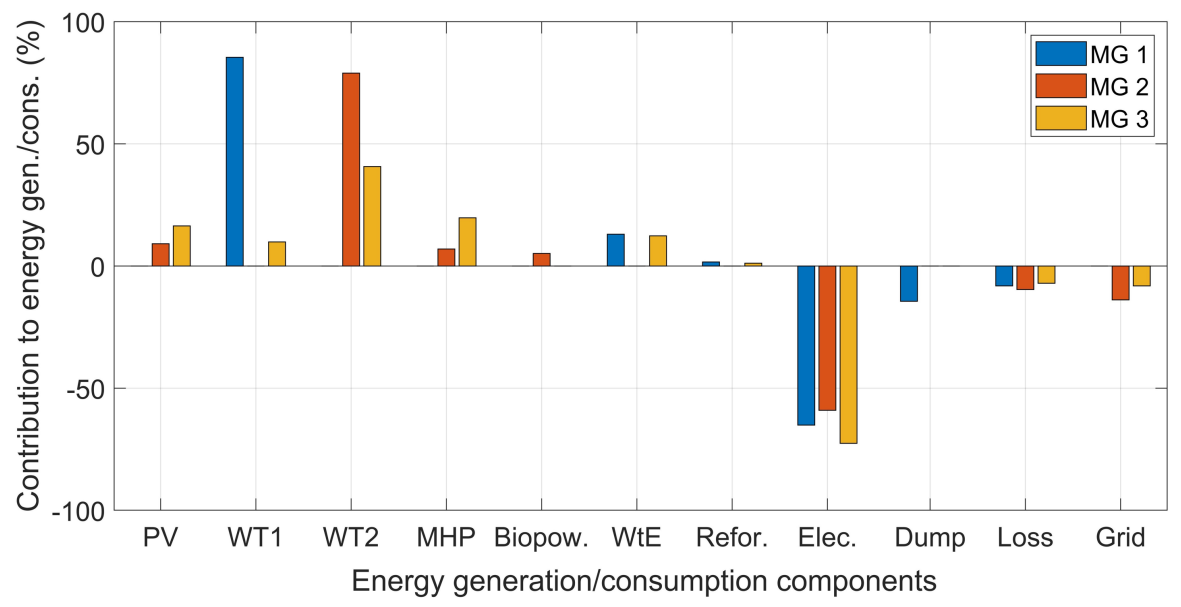

Fig. 16. Breakdown of the generated/consumed energy within the conceptualised MGs.

The following points can be made with regard to the results presented in Figs. 15 and 16:

1. The negative values of the total amounts of energy exchanged with the upstream network in the cases of gridconnected MGs (i.e. MG 2 and MG 3) indicate that the energy trading between the MGs and the network has made direct profits for them, thereby reducing their expected TNPCs. Much of the reason for this lies in avoiding the circulation of the excess energy through a dump load by selling it to the network. Utilising the 
support of the grid for satisfying the sporadic peak demands (not seasonal) is another reason, which, to some extent, contributes to the energy affordability in the second and third MGs.

2. The significant contributions of wind energy technologies to the TNPCs of all the three MGs, along with the substantial contributions of the wind generation systems to the total energy generation within these MGs, collectively imply that the examined sites are rich in wind resources.

3. There are neither electrical nor hydrogen unmet loads on the consumption sides, which is due to the reliability constraints (LPSP $=0$ ) imposed on the optimization protocol.

4. The obtained optimum solution sets for the MGs' components indicate a diversification in the respective energy mixes of the MG network, whereby the security of energy supply is strengthened. Put differently, the obtained results have not avoided any source of energy considered. This further verifies the efficacy of the proposed methodology.

\subsection{Validation of the models}

In order to further validate the financial sustainability of the considered projects, a comprehensive evaluation of the projected costs and profits based on the following three criteria for investment analysis is carried out with: (1) the discounted payback period (DPP), (2) the profitability index (PI), and (3) the internal rate of return (IRR).

The DPP criterion conciliates the classic payback period technique with the discounted cash flow analysis to calculate the break-even point, after which an investment plan makes profit taking into account the discount rate, which was first proposed by Irving Fisher [113]. The criterion can be adapted for application in the field of MG design and planning as follows:

$$
\sum_{t=0}^{D P P} S(1+i r)^{-t}-T N P C=0,
$$

where $S$ is the annual income created by selling energy to the consumers of the MG and from selling the electricity to the upstream power grid (where applicable). In this analysis, we have assumed a flat charge of $\$ 0.26 / \mathrm{kWh}$, in New Zealand currency, for MG 1 and a flat-rate electricity tariff of $\$ 0.21 / \mathrm{kWh}$ for MGs 2 and 3, as well as a hydrogen price of $\$ 14 / \mathrm{kg} \mathrm{H}_{2}$ for all the three MG samples. These prices are in accordance with the service prices presently available at the studied sites in their energy sectors.

The PI is defined as the ratio of the present value of the total investment expenditure of a business plan across its lifetime to its initial investment cost, i.e. the ratio of payoff to the investment of a project [114]. The following equation can be used to adapt the PI index in the MG design studies:

$$
P I=100 \times \frac{\sum_{t=0}^{R} S(1+i r)^{-t}-T N P C}{\operatorname{Cap}_{T}},
$$

where $R$ denotes the lifetime of the MG system and $\operatorname{Cap}_{T}$ represents the total capital costs of the MG components in the base year.

The IRR is defined as the discount rate, which makes the TNPC of an investment project equal to zero, thereby leading the investment to break even before it starts obtaining any incomes, whose higher values indicate the higher robustness of the investment analyses [115]. In order to adapt the IRR metric in the application of MG planning, the following equation can be utilised:

$$
\sum_{t=0}^{R} \frac{C F(t)}{(1+i r)^{t}}=0,
$$

where $C F(t)$ represents the net cash inflow in the $t$-th year of investment.

Table 6 presents the DPP, the PI, and the IRR of the MG projects, whose economic sustainability are under evaluation. The table demonstrates that these projects are not only financially profitable to undertake, but also can be characterised as low-risk, high-yield investment opportunities. 
Table 6. Economic sustainability assessment of the MG projects under study.

\begin{tabular}{cccc}
\hline Test-case system & DPP (year) & PI (\%) & IRR (\%) \\
\hline MG 1 & 8.60 & 2.28 & 13.49 \\
MG 2 & 7.95 & 2.77 & 14.72 \\
MG 3 & 7.23 & 3.01 & 15.18 \\
\hline
\end{tabular}

\section{Conclusions and future work}

In this paper, the performances of twenty meta-heuristic optimization algorithms, including both traditional and recently developed techniques (and involving single and hybrid algorithms), are evaluated for MG optimal design and equipment capacity planning applications. The evaluations are made based on three hydrogen-based MG test-case systems, proposed to bring sustainable electricity and transportation fuel to remote, rural, and semi-urban communities. Furthermore, a new statistical performance comparison framework, improved by the consideration of the number of hits to the global optima throughout a certain number of trials, is devised. The performance assessments indicate that it is important to put into test the state-of-the-art meta-heuristics, since they are theoretically able to outperform the traditional ones in terms of solution quality and/or convergence speed. Specifically, the MFOA has shown a better efficiency in nearing the global optimum solution sets when applied to MG capacity planning studies in comparison with the nineteen other new and traditional meta-heuristics analysed in this study. More specifically, the numerical tests carried out in this study have revealed that the relative error in estimating the globally optimum solutions of the least-cost MG designs using the selected metaheuristics could go as high as $2.4 \%, 1.6 \%$, and $6.5 \%$ respectively from the three target systems - equating to cost savings of $\$ 216,922, \$ 683,878$, and $\$ 346,180$, respectively. The statistical tests also prove that many of the algorithms have nearly the same efficiencies, when assessed on the basis of their performances on different MG test-case systems with different climatic and loading conditions. Noticeably, an increased number of test systems and/or independent runs will tend to improve the validity of the conclusions drawn on the superior performance of the algorithms under evaluation.

A novel energy management plan is also designed to cost-effectively integrate the heavy- and light-duty hydrogen fuel cell-powered vehicles, as well as hydrogen-powered vessels, into the $100 \%$ renewable MG networks with the objective of facilitating the decarbonisation of the transport sector. The hydrogen-based MGs conceptualised in this study have provided effective platforms for the hydrogen production through water electrolysis and gasification of biomass resources (i.e. the non-organic fraction of MSW as well as the agricultural biomass). Thus, they can effectively contribute to unlocking the potential of hydrogen as a clean, reliable, affordable, locally-controlled energy carrier to address the energy needs of both remote and non-remote communities, which, in turn, can make a significant contribution towards achieving the sustainable development goals.

Future work will investigate the incorporation of the following features in the devised generic MG sizing framework towards reflecting the real-world practice in a more accurate fashion in the long-term investment planning phase of renewable and sustainable energy systems: (1) taking into account dynamic efficiencies for the components of MGs, especially the components adopted within the hydrogen sub-systems, whereby the degradation of the components over their service lives is effectively addressed; (2) integration of the uncertainties associated with different variables (e.g. energy demand, load growth, energy supply, system losses, atmospheric conditions, storage capacity, etc.) within the system; and (3) consideration of the power quality issues related to the harmonics generated by renewable power conversion systems and nonlinear loads into the model.

\section{References}

[1] W. Ongsakul and V. N. Dieu, Artificial intelligence in power system optimization. CRC Press, Inc., 2013.

[2] J. Zhao, H. S. Ramadan, and M. Becherif, "Metaheuristic-based energy management strategies for fuel cell emergency power unit in electrical aircraft," Int. J. Hydrogen Energy, vol. 44, no. 4, pp. 2390-2406, 2019.

[3] A. Tabanjat, M. Becherif, D. Hissel, and H. S. Ramadan, "Energy management hypothesis for hybrid power system of H2/WT/PV/GMT via AI techniques," Int. J. Hydrogen Energy, vol. 43, no. 6, pp. 3527-3541, 2018.

[4] P. B. de M. Oliveira and J. B. Cunha, "Blending Artificial Intelligence into PID Controller Design: A 
Biomedical Engineering Experiment," IFAC-PapersOnLine, vol. 49, no. 6, pp. 366-371, 2016.

[5] B. V. Mathiesen et al., "Smart Energy Systems for coherent 100\% renewable energy and transport solutions," Appl. Energy, vol. 145, pp. 139-154, 2015.

[6] S. M. Moghaddas-Tafreshi, M. Jafari, S. Mohseni, and S. Kelly, "Optimal operation of an energy hub considering the uncertainty associated with the power consumption of plug-in hybrid electric vehicles using information gap decision theory," Int. J. Electr. Power Energy Syst., vol. 112, pp. 92-108, 2019.

[7] A. G. De Crisci, A. Moniri, and Y. Xu, "Hydrogen from hydrogen sulfide: towards a more sustainable hydrogen economy," Int. J. Hydrogen Energy, vol. 44, no. 3, pp. 1299-1327, 2019.

[8] A. G. Stern, “A new sustainable hydrogen clean energy paradigm," Int. J. Hydrogen Energy, vol. 43, no. 9, pp. 4244-4255, 2018.

[9] C. Acar, A. Beskese, and G. T. Temur, "Sustainability analysis of different hydrogen production options using hesitant fuzzy AHP," Int. J. Hydrogen Energy, vol. 43, no. 39, pp. 18059-18076, 2018.

[10] C. Gamarra and J. M. Guerrero, "Computational optimization techniques applied to microgrids planning: A review,” Renew. Sustain. Energy Rev., vol. 48, pp. 413-424, 2015.

[11] N. D. Hatziargyriou, D. Škrlec, T. Capuder, P. S. Georgilakis, and M. Zidar, "Review of energy storage allocation in power distribution networks: applications, methods and future research," IET Gener. Transm. Distrib., vol. 10, no. 3, pp. 645-652, 2016.

[12] S. M. Hakimi, S. M. M. Tafreshi, and A. Kashefi, "Unit sizing of a stand-alone hybrid power system using Particle Swarm Optimization (PSO)," in Proceedings of the 2007 IEEE International Conference on Automation and Logistics, Jinan, China, 18-21 Aug. 2007, pp. 3107-3112.

[13] S. M. Sadeghzadeh and M. Ansarian, "Distributed Generation and Renewable Planning with a Linear Programming Model," in Proceedings of the $1^{\text {st }}$ Int. Power and Energy Conf., Putrajaya, Malaysia, 28-29 Nov. 2006, pp. 48-53.

[14] C. H. Lo and M. D. Anderson, "Economic dispatch and optimal sizing of battery energy storage systems in utility load-leveling operations," IEEE Trans. Energy Convers., vol. 14. no. 3, pp. 824-829, 1999.

[15] C. Brunetto and G. Tina, "Optimal hydrogen storage sizing for wind power plants in day ahead electricity market," IET Renew. Power Gener., vol. 1, no. 4, pp. 220-226, 2007.

[16] C. Marnay, G. Venkataramanan, M. Stadler, A. Siddiqui, R. Firestone, and B. Chandran, "Optimal Technology Selection and Operation of Commercial-Building Microgrids," IEEE Trans. Power Syst., vol. 23, no. 3, pp. 975-982, 2008.

[17] C. A. Hernandez-Aramburo, T. C. Green, and N. Mugniot, "Fuel consumption minimisation of a micro-grid," IEEE Trans. Ind. Appl., vol. 41, no. 3, pp. 673-681, 2005.

[18] N. Mohandas, R. Balamurugan, and L. Lakshminarasimman, "Optimal location and sizing of real power DG units to improve the voltage stability in the distribution system using ABC algorithm united with chaos," Int. J. Electr. Power Energy Syst., vol. 66, pp. 41-52, 2015.

[19] G. Derakhshan, H. A. Shayanfar, and A. Kazemi, "Optimal design of solar PV-WT-SB based smart microgrid using NSHCSO,” Int. J. Hydrogen Energy, vol. 41, no. 44, pp. 19947-19956, 2016.

[20] B. Bahmani-Firouzi and R. Azizipanah-Abarghooee, "Optimal sizing of battery energy storage for micro-grid operation management using a new improved bat algorithm," Int. J. Electr. Power Energy Syst., vol. 56, pp. 42-54, 2014.

[21] A. Lorestani, G. B. Gharehpetian, and M. H. Nazari, "Optimal sizing and techno-economic analysis of energyand cost-efficient standalone multi-carrier microgrid," Energy, vol. 178, pp. 751-764, 2019.

[22] S. Sheng and J. Zhang, "Capacity configuration optimisation for stand-alone micro-grid based on an improved binary bat algorithm,” J. Eng., vol. 2017, no. 13, pp. 2083-2087, 2017.

[23] P. Nagapurkar and J. D. Smith, "Techno-economic optimization and environmental Life Cycle Assessment (LCA) of microgrids located in the US using genetic algorithm," Energy Convers. Manag., vol. 181, pp. 272- 
292, 2019.

[24] S. M. Hakimi, A. Hasankhani, M. Shafie-khah, and J. P. S. Catalão, IET Renew. Power Gener., vol. 13, no. 10, pp. 1809-1822, 2019.

[25] S. Sharma, S. Bhattacharjee, and A. Bhattacharya, "Grey wolf optimisation for optimal sizing of battery energy storage device to minimise operation cost of microgrid," IET Gener. Transm. Distrib., vol. 10, no. 3, pp. 625-637, 2016.

[26] A. Maleki and F. Pourfayaz, "Sizing of stand-alone photovoltaic/wind/diesel system with battery and fuel cell storage devices by harmony search algorithm," J. Energy Storage, vol. 2, pp. 30-42, 2015.

[27] S. Singh, M. Singh, and S. C. Kaushik, "Feasibility study of an islanded microgrid in rural area consisting of PV, wind, biomass and battery energy storage system," Energy Convers. Manag., vol. 128, pp. 178-190, 2016.

[28] A. Fetanat and E. Khorasaninejad, "Size optimization for hybrid photovoltaic-wind energy system using ant colony optimization for continuous domains based integer programming," Appl. Soft Comput. J., vol. 31, pp. 196-209, 2015.

[29] M. Kefayat, A. Lashkar Ara, and S. A. Nabavi Niaki, "A hybrid of ant colony optimization and artificial bee colony algorithm for probabilistic optimal placement and sizing of distributed energy resources," Energy Convers. Manag., vol. 92, pp. 149-161, 2015.

[30] A. L. Bukar, C. W. Tan, and K. Y. Lau, "Optimal sizing of an autonomous photovoltaic/wind/battery/diesel generator microgrid using grasshopper optimization algorithm,” Sol. Energy, vol. 188, pp. 685-696, 2019.

[31] M. Tolba, H. Rezk, A. A. Z. Diab, and M. Al-Dhaifallah, "A Novel Robust Methodology Based Salp Swarm Algorithm for Allocation and Capacity of Renewable Distributed Generators on Distribution Grids," Energies, vol. 11, no. 10, p. 2556, 2018.

[32] E. S. Ali, S. M. Abd Elazim, and A. Y. Abdelaziz, "Optimal allocation and sizing of renewable distributed generation using ant lion optimization algorithm," Electr. Eng., vol. 100, no. 1, pp. 99-109, 2018.

[33] N. Ghorbani, A. Kasaeian, A. Toopshekan, L. Bahrami, and A. Maghami, "Optimizing a Hybrid Wind-PVBattery System Using GA-PSO and MOPSO for Reducing Cost and Increasing Reliability," Energy, vol. 154, pp. 581-591, 2017.

[34] D. Sharma, P. Gaur, and A. P. Mittal, "Comparative Analysis of Hybrid GAPSO Optimization Technique With GA and PSO Methods for Cost Optimization of an Off-Grid Hybrid Energy System," Energy Technol. Policy, vol. 1, no. 1, pp. 106-114, 2014.

[35] D. Yang, C. Jiang, G. Cai, and N. Huang, "Optimal sizing of a wind/solar/battery/diesel hybrid microgrid based on typical scenarios considering meteorological variability," IET Renew. Power Gener., vol. 13, no. 9, pp. 1446-1455, 2019.

[36] M. Gharibi and A. Askarzadeh, "Size and power exchange optimization of a grid-connected diesel generatorphotovoltaic-fuel cell hybrid energy system considering reliability, cost and renewability," Int. J. Hydrogen Energy, In Press, 2019.

[37] W. Peng, A. Maleki, M. A. Rosen, and P. Azarikhah, "Optimization of a hybrid system for solar-wind-based water desalination by reverse osmosis: Comparison of approaches," Desalination, vol. 442, pp. 16-31, 2018.

[38] D. H. Wolpert and W. G. Macready, "No free lunch theorems for optimization," IEEE Trans. Evol. Comput., vol. 1, no. 1, pp. 67-82, 1997.

[39] J. D. Fonseca, M. Camargo, J.-M. Commenge, L. Falk, and I. D. Gil, "Trends in design of distributed energy systems using hydrogen as energy vector: A systematic literature review," Int. J. Hydrogen Energy, vol. 44, no. 19, pp. 9486-9504, 2019.

[40] J. Kennedy and R. C. Eberhart, "Particle swarm optimization," in Proceedings of the 1995 IEEE International Conference on Neural Networks, Perth, WA, Australia, 27 Nov.-1 Dec. 1995, vol. 4, pp. 1942-1948.

[41] D. E. Goldberg and J. H. Holland, "Genetic Algorithms and Machine Learning," Mach. Learn., vol. 3, pp. 9599, 1988. 
[42] Y. T. Kao and E. Zahara, "A hybrid genetic algorithm and particle swarm optimization for multimodal functions," Appl. Soft Comput. J., vol. 8, no. 2, pp. 849-857, 2008.

[43] D. Karaboga, An Idea Based On Honey Bee Swarm For Numerical Optimization. Technical Report-TR06, Erciyes University, Engineering Faculty, Computer Engineering Department, 2005.

[44] M. Dorigo and G. Di Caro, "Ant Colony Optimization: A New Meta-Heuristic," in Proceedings of the 1999 Congr. Evol. Comput., Washington, DC, USA, 6-9 Jul. 1999, pp. 1470-1477.

[45] P. Ganeshkumar, C. Rani, D. Devaraj, and T. Aruldoss Albert Victoire, "Hybrid ant bee algorithm for fuzzy expert system based sample classification," IEEE/ACM Trans. Comput. Biol. Bioinforma., vol. 11, no. 2, pp. 347-360, 2014.

[46] S. Mirjalili, “The ant lion optimizer,” Adv. Eng. Softw., vol. 83, pp. 80-98, 2015.

[47] M. Mahdavi, M. Fesanghary, and E. Damangir, "An improved harmony search algorithm for solving optimization problems," Appl. Math. Comput., vol. 188, no. 2, pp. 1567-1579, 2007.

[48] O. K. Erol and I. Eksin, "A new optimization method: Big Bang-Big Crunch,” Adv. Eng. Softw., vol. 37, no. 2, pp. 106-111, 2006.

[49] S. Mirjalili, "Moth-flame optimization algorithm: A novel nature-inspired heuristic paradigm," KnowledgeBased Syst., vol. 89, pp. 228-249, 2015.

[50] S. Mirjalili, "SCA: A Sine Cosine Algorithm for solving optimization problems," Knowledge-Based Syst., vol. 96, pp. 120-133, 2016.

[51] S. Mirjalili, S. M. Mirjalili, and A. Hatamlou, "Multi-Verse Optimizer: a nature-inspired algorithm for global optimization," Neural Comput. Appl., vol. 27, no. 2, pp. 495-513, 2016.

[52] A. Kaveh and T. Bakhshpoori, "Water Evaporation Optimization: A novel physically inspired optimization algorithm,” Comput. Struct., vol. 167, pp. 69-85, 2016.

[53] S. Mirjalili, S. M. Mirjalili, and A. Lewis, "Grey Wolf Optimizer," Adv. Eng. Softw., vol. 69, pp. 46-61, 2014.

[54] X.-S. Yang and S. Deb, "Engineering Optimisation by Cuckoo Search," Int. J. Math. Model. Numer. Optim., vol. 1, no. 4, pp. 330-343, 2010.

[55] S. Mirjalili, A. H. Gandomi, S. Z. Mirjalili, S. Saremi, H. Faris, and S. M. Mirjalili, "Salp Swarm Algorithm: A bio-inspired optimizer for engineering design problems," Adv. Eng. Softw., vol. 114, pp. 163-191, 2017.

[56] S. Saremi, S. Mirjalili, and A. Lewis, "Grasshopper Optimisation Algorithm: Theory and application," Adv. Eng. Softw., vol. 105, pp. 30-47, 2017.

[57] S. Mirjalili, "Dragonfly algorithm: a new meta-heuristic optimization technique for solving single-objective, discrete, and multi-objective problems," Neural Comput. Appl., vol. 27, no. 4, pp. 1053-1073, 2016.

[58] X.-S. Yang, A New Metaheuristic Bat-Inspired Algorithm. In: González J.R., Pelta D.A., Cruz C., Terrazas G., Krasnogor N. (eds) Nature Inspired Cooperative Strategies for Optimization (NICSO 2010). Studies in Computational Intelligence, vol. 284. Springer, 2010.

[59] X.-S. Yang, Nature-inspired metaheuristic algorithms. Luniver Press, 2008.

[60] S. Podder and M. Z. R. Khan, "Comparison of lead acid and Li-ion battery in solar home system of Bangladesh," in Proceedings of the 5th Int. Conf. Informatics, Electron. Vision, Dhaka, Bangladesh, 13-14 May 2016, pp. 434-438.

[61] G. Kyriakarakos, D. D. Piromalis, K. G. Arvanitis, A. I. Dounis, and G. Papadakis, "On battery-less autonomous polygeneration microgrids: Investigation of the combined hybrid capacitors/hydrogen alternative," Energy Convers. Manag., vol. 91, pp. 405-415, 2015.

[62] C. Li et al., "Evaluation of wind energy resource and wind turbine characteristics at two locations in China," Technol. Soc., vol. 47, pp. 121-128, 2016.

[63] M. H. Amrollahi and S. M. T. Bathaee, "Techno-economic optimization of hybrid photovoltaic/wind generation together with energy storage system in a stand-alone micro-grid subjected to demand response," 
Appl. Energy, vol. 202, pp. 66-77, 2017.

[64] M. M. V. Leme, M. H. Rocha, E. E. S. Lora, O. J. Venturini, B. M. Lopes, and C. H. Ferreira, "Technoeconomic analysis and environmental impact assessment of energy recovery from Municipal Solid Waste (MSW) in Brazil," Resour. Conserv. Recycl., vol. 87, pp. 8-20, 2014.

[65] U. Akram, M. Khalid, and S. Shafiq, "An innovative hybrid wind-solar and battery-supercapacitor microgrid system — development and optimization," IEEE Access, vol. 5, pp. 25897-25912, 2017.

[66] F. Xu, J. Liu, S. Lin, Q. Dai, and C. Li, "A multi-objective optimization model of hybrid energy storage system for non-grid-connected wind power: A case study in China," Energy, vol. 163, pp. 585-603, 2018.

[67] H. HassanzadehFard, S. M. Moghaddas-Tafreshi, and S. M. Hakimi, "Effect of energy storage systems on optimal sizing of islanded micro-grid considering interruptible loads," in Proceedings of the 2011 3rd Int. Youth Conf. Energ., Leiria, Portugal, 7-9 Jul. 2011, pp. 1-7.

[68] A. C. Duman and Ö. Güler, "Techno-economic analysis of off-grid PV/wind/fuel cell hybrid system combinations with a comparison of regularly and seasonally occupied households," Sustain. Cities Soc., vol. 42, pp. 107-126, 2018.

[69] S. Mohseni and S. M. Moghaddas-Tafreshi, "A multi-agent system for optimal sizing of a cooperative selfsustainable multi-carrier microgrid," Sustain. Cities Soc., vol. 38, pp. 452-465, 2018.

[70] Y. Zheng, B. M. Jenkins, K. Kornbluth, and C. Træholt, "Optimization under uncertainty of a biomassintegrated renewable energy microgrid with energy storage," Renew. Energy, vol. 123, pp. 204-217, 2018.

[71] S. M. Hakimi and S. M. Moghaddas-Tafreshi, "Optimal sizing of a stand-alone hybrid power system via particle swarm optimization for Kahnouj area in south-east of Iran," Renew. Energy, vol. 34, no. 7, pp. 1855$1862,2009$.

[72] S. M. Hakimi, S. M. Moghaddas-Tafreshi, and H. HassanzadehFard, "Optimal sizing of reliable hybrid renewable energy system considered various load types,” J. Renew. Sustain. Energy, vol. 3, 062701, 2011.

[73] A. Kashefi Kaviani, G. H. Riahy, and S. M. Kouhsari, "Optimal design of a reliable hydrogen-based standalone wind/PV generating system, considering component outages," Renew. Energy, vol. 34, no. 11, pp. 23802390, 2009.

[74] U. Mukherjee et al., "Techno-economic, environmental, and safety assessment of hydrogen powered community microgrids; case study in Canada," Int. J. Hydrogen Energy, vol. 42, no. 20, pp. 14333-14349, 2017.

[75] G. Dispenza et al., "Development of a solar powered hydrogen fueling station in smart cities applications," Int. J. Hydrogen Energy, vol. 42, no. 46, pp. 27884-27893, 2017.

[76] C. He, H. Sun, Y. Xu, and S. Lv, "Hydrogen refueling station siting of expressway based on the optimization of hydrogen life cycle cost," Int. J. Hydrogen Energy, vol. 42, no. 26, pp. 16313-16324, 2017.

[77] F. Grüger, L. Dylewski, M. Robinius, and D. Stolten, "Carsharing with fuel cell vehicles: Sizing hydrogen refueling stations based on refueling behavior," Appl. Energy, vol. 228, pp. 1540-1549, 2018.

[78] Anonymous, "Hydrogen fueling staion," 2018. [Online]. Available: https://pureenergycentre.com/hydrogenfueling-station/. [Accessed: 29-Apr.-2019].

[79] Anonymous, "Hydrogenesis Passenger Ferry." [Online]. Available: https://www.shiptechnology.com/projects/hydrogenesis-passenger-ferry/. [Accessed: 29-Apr.-2019].

[80] M. R. Basir Khan, R. Jidin, and J. Pasupuleti, "Multi-agent based distributed control architecture for microgrid energy management and optimization," Energy Convers. Manag., vol. 112, pp. 288-307, 2016.

[81] S. X. Chen, H. B. Gooi, and M. Q. Wang, "Sizing of energy storage for microgrids," IEEE Trans. Smart Grid, vol. 3, no. 1, pp. 142-151, 2012.

[82] N. Yamada and M. N. A. Mohamad, "Efficiency of hydrogen internal combustion engine combined with open steam Rankine cycle recovering water and waste heat," Int. J. Hydrogen Energy, vol. 35, no. 3, pp. 1430$1442,2010$. 
[83] L. V. White, B. Lloyd, and S. J. Wakes, "Are Feed-in Tariffs suitable for promoting solar PV in New Zealand cities?,” Energy Policy, vol. 60, pp. 167-178, 2013.

[84] S. M. Moghaddas-Tafreshi, S. Mohseni, M. E. Karami, and S. Kelly, "Optimal energy management of a gridconnected multiple energy carrier micro-grid,” Appl. Therm. Eng., vol. 152, pp. 796-806, 2019.

[85] H. Qin and J. W. Kimball, "Solid-state transformer architecture using AC-AC dual-active-bridge converter," IEEE Trans. Ind. Electron., vol. 60, no. 9, pp. 3720-3730, 2013.

[86] P. Horrell, "This Riversimple Rasa hydrogen car wants to save the world," 2018. [Online]. Available: https://www.topgear.com/car-news/big-reads/riversimple-rasa-hydrogen-car-wants-save-world/. [Accessed: 29-Apr.-2019].

[87] Anonymous, "Hyundai and H2 Energy to launch world's first fleet of Fuel Cell Truck," 2018. [Online]. Available: https://www.hyundai.news/uk/model-news/hyundai-motor-and-h2-energy-will-bring-the-worldsfirst-fleet-of-fuel-cell-electric-truck-into-commercial-operation/. [Accessed: 29-Apr.-2019].

[88] Anonymous, "New Holland's NH2 fuel cell powered tractor to enter service," Fuel Cells Bull., vol. 2012, no. 1, pp. 3-4, 2012.

[89] G. Mavrotas, K. Florios, and D. Vlachou, "Energy planning of a hospital using Mathematical Programming and Monte Carlo simulation for dealing with uncertainty in the economic parameters," Energy Convers. Manag., vol. 51, no. 4, pp. 722-731, 2010.

[90] E. Ofry and A. Braunstein, "The Loss of Power Supply Probability as a Technique for Designing Stand-Alone Solar Electrical (Photovoltaic) Systems," IEEE Power Eng. Rev., vol. PER-3, no. 5, pp. 34-35, 1983.

[91] O. Hafez and K. Bhattacharya, "Optimal planning and design of a renewable energy based supply system for microgrids," Renew. Energy, vol. 45, pp. 7-15, 2012.

[92] Business borrowing rates, 2019. [Online]. Available: https://www.interest.co.nz/borrowing/business-baserates/. [Accessed: 29-Apr.-2019].

[93] Discount Rates and CPI Assumptions for Accounting Valuation Purposes, 2019. [Online]. Available: https://treasury.govt.nz/information-and-services/state-sector-leadership/guidance/financial-reportingpolicies-and-guidance/discount-rates/discount-rates-and-cpi-assumptions-accounting-valuation-purposes/. [Accessed: 29-Apr.-2019].

[94] D A. P. Agalgaonkar, C. V. Dobariya, M. G. Kanabar, S. A. Khaparde, and S. V. Kulkarni "Optimal sizing of distributed generators in microgrid," in Proceedings of the 2006 IEEE Power India Conf., New Delhi, India, 10-12 Apr. 2006, pp. 901-908.

[95] H. Lotfi and A. Khodaei, "Levelized cost of energy calculations for microgrids," in Proceedings of the 2016 IEEE Power Energy Soc. Gen. Meet., Boston, MA, USA, 17-21 Jul. 2016, pp. 1-5.

[96] H. HassanzadehFard, S. M. Moghaddas-Tafreshi, and S. M. Hakimi, "Optimization of grid-connected microgrid consisting of PV/FC/UC with considered frequency control," Turk. J. Elec. Eng. Comp. Sci., vol. 23, pp. 1-16, 2015.

[97] New Zealand Lifelines Council Members, New Zealand Lifelines Infrastructure Vulnerability Assessment: Stage 1, 2017. Available: https://www.civildefence.govt.nz/assets/Uploads/lifelines/National-VulnerabilityAssessment-Stage-1-September-2017.pdf/.

[98] I. G. Mason and R. G. Mcneill, "Edging towards sustainability-a 100\% renewable electricity system for Stewart Island," in Proceedings of the EEA Conf. and Exhib., Wellington, New Zealand, 22-24 Jun. 2016, pp. $1-10$.

[99] J. Anderson, Pulling the Plug on Network Congestion. University of Otago, 2009. Available: https://www.parliament.nz/resource/0000100131/.

[100] D. Gandini and A. T. de Almeida, "Direct current microgrids based on solar power systems and storage optimization, as a tool for cost-effective rural electrification," Renew. Energy, vol. 111, pp. 275-283, 2017.

[101] U. S. Magarappanavar and S. Koti, "Optimization of Wind-Solar-Diesel Generator Hybrid Power System 
using HOMER," Int. Res. J. Eng. Technol., vol. 3, no. 6, pp. 522-526, 2016.

[102] W. Zhang, A. Maleki, and M. A. Rosen, "A heuristic-based approach for optimizing a small independent solar and wind hybrid power scheme incorporating load forecasting," J. Clean. Prod., vol. 241, 117920, 2019.

[103] A. Abdelkader, A. Rabeh, D. Mohamed Ali, and J. Mohamed, "Multi-objective genetic algorithm based sizing optimization of a stand-alone wind/PV power supply system with enhanced battery/supercapacitor hybrid energy storage," Energy, vol. 163, pp. 351-363, 2018.

[104] M. Gökçek and C. Kale, "Optimal design of a Hydrogen Refuelling Station (HRFS) powered by Hybrid Power System,” Energy Convers. Manag., vol. 161, pp. 215-224, 2018.

[105] S. Mohseni and S.M. Moghaddas-Tafreshi, "Development of a Multi-Agent System for Optimal Sizing of a Commercial Complex Microgrid," arXiv preprint, arXiv:1811.12553, 2018.

[106] S. Mohseni and S.M. Moghaddas-Tafreshi, "A Multi-Agent Approach to Optimal Sizing of a Combined Heating and Power Microgrid," arXiv preprint, arXiv:1812.11076, 2018.

[107] CliFlo: NIWA's National Climate Database on the Web. [Data Collection]. Available: http://cliflo.niwa.co.nz/. [Retrieved: 13-Apr.-2019].

[108] B. Anderson et al., New Zealand GREEN Grid Household Electricity Demand Study 2014-2018. [Data Collection]. Colchester, Essex: UK Data Service. http://dx.doi.org/10.5255/UKDA-SN-853334.

[109] V. G. Kulkarni, Modeling, analysis, design, and control of stochastic systems, (1st ed.). Springer, 1999.

[110] MATLAB, 2018. Version 9.5 (R2018b), Natick, Massachusetts: The MathWorks Inc.

[111] M. Watson, "Could hydrogen turn Taranaki into the Norway of the Pacific?," 2018. [Online]. Available: https://www.stuff.co.nz/environment/105601987/could-hydrogen-turn-taranaki-into-the-norway-of-thepacific/. [Accessed: 29-Apr.-2019].

[112] Concept Consulting Group Ltd., Hydrogen in New Zealand Report 1 - Summary, 2019. Available: http://www.concept.co.nz/uploads/2/5/5/4/25542442/h2_report1_summary_v4.pdf.

[113] I. Fisher, The theory of interest, as determined by impatience to spend income and opportunity to invest it. Macmillan, 1930.

[114] D. L. Talavera, E. Muñoz-Cerón, J. P. Ferrer-Rodríguez, and P. J. Pérez-Higueras, "Assessment of costcompetitiveness and profitability of fixed and tracking photovoltaic systems: The case of five specific sites," Renew. Energy, vol. 134, pp. 902-913, 2019.

[115] I. Bendato et al., "Design criteria for the optimal sizing of integrated photovoltaic-storage systems," Energy, vol. 149, pp. 505-515, 2018. 